\title{
MONITOREO TELEMÁTICO: ANÁLISIS CRÍTICO DESDE LA SOCIOLOGÍA DEL CONTROL Y LA ECONOMÍA POLÍTICA DEL CASTIGO*
}

\author{
Electronic Monitoring: \\ critical analysis from control sociology and the political economy of power
}

Ignacio Peña Caroca ${ }^{* *}$

\begin{abstract}
Resumen: El presente trabajo tiene por objeto, en primer lugar, llevar a cabo un análisis de la evolución, implementación y significado del monitoreo telemático en Chile. Este instrumento se introdujo en nuestro país, por medio de la Ley $\mathrm{N}^{\circ}$ 20.603, para complementar y reforzar dos medidas sustitutivas a la privación de libertad: reclusión parcial y libertad vigilada intensiva. En segundo lugar, pretende revisar su aplicación y efectos en el derecho comparado. Así, el estudio persigue develar la finalidad de la pulsera electrónica y su introducción en el derecho chileno, en un contexto de ausencia de debate público en su implementación. En este sentido, busca evidenciar que el objetivo de la medida es otorgarle la facultad al Estado para intervenir, por medio de la vigilancia y el control, en un espacio que, previo a la reforma, no podía acceder, a saber, la libertad del sujeto en sociedad. En tercer lugar, busca cuestionar la aplicación del instrumento, sosteniendo que constituye un mecanismo de vigilancia, normalización y control del cuerpo del individuo, que asume el fracaso rehabilitador de la prisión y centra sus efectos simbólicos en la violencia hacia el sujeto y en la diseminación del control en la sociedad. En cuarto lugar, se sostiene, constituye una medida que representa el ideal privatizador de la justicia, propio del Workfare, por medio de la instalación de un discurso carcelario y empresarial en las prácticas punitivas del Estado. Esto tendría como consecuencia el fin de los lazos comunitarios en la sociedad.
\end{abstract}

Palabras clave: monitoreo telemático - medidas sustitutivas a la privación de libertad control - vigilancia - castigo.

\begin{abstract}
The purpose of this work is to carry out an analysis of the evolution, implementation and significance of the Electronic Monitoring in Chile. This instrument was introduced in our country through law 20.603, to complement and reinforce two amended measures to deprivation of liberty: parcial imprisonment and probation. Secondly, this study attempts to review its application and effects in comparative law. Thus, this study seeks to unveil the purpose of the electronic wristband and its introduction in chilean law, in a context of absence of public debate regarding its implementation. In this sense, it tries to demonstrate that the purpose of this measure is to give the State the ability to intervene, through vigilance and control, in a scope that it

\footnotetext{
* Una primera versión de este trabajo fue presentado en el curso "Delito y Control Social" en la Facultad de Derecho de la Universidad de Chile, a cargo de la profesora María Inés Horvitz. Agradezco a su persona, a Guillermo Silva y, sobre todo, a Isabel Arriagada por sus lúcidas críticas y por el apoyo brindado desde el inicio de esta investigación.

** Estudiante Facultad de Derecho, Universidad de Chile. Correo electrónico: ipena@lmrycia.cl.
}

Este artículo fue recibido el 8 de mayo de 2013, siendo aprobada su publicación con fecha 24 de junio de 2013. 
Peña - Monitoreo telemático...

couldn't do before the reform, id est, the subject's liberty in society. In third place, this work questions the application of this instrument, affirming that it becomes a surveillance mechanism, normalization and control of the individual's body, recognizes the reformative failure of prison and centres its simbolic effects in violence towards the subject and in the dissemination of control in society. Lastly, it is sustained in this work that EM is a measure that represents the privatisation ideal of justice, a characteristic of the Workfare, through the instalation of a prison and business speech in the State's punitive practices. This would have as consequence the ending of community bonds on society.

Keywords: electronic monitoring - probation - control - surveillance - punishment.

\section{Introducción}

En este trabajo nos proponemos llevar a cabo un análisis acerca de la evolución, aplicación y significado del monitoreo telemático y su aplicación en Chile. Tanto a nivel de investigación como de debate, la introducción de la monitorización ha pasado casi inadvertida. Es por esta razón que se intentará dar una explicación general de la medida y de llevar a cabo una evaluación crítica, tanto en términos jurídicos como sociológicos.

Para tal objeto, en el primer capítulo de este trabajo nos proponemos ofrecer una evolución histórica de la medida. En Estados Unidos el monitoreo telemático posee tres fases de desarrollo, a saber, desde principios de la década de los 60 hasta mediados de los 70, desde mediados de los 70 hasta 1984 y, desde este año (fecha en la que se impuso por primera vez el uso del dispositivo) hasta la actualidad.

En la segunda parte de este capítulo se describe brevemente la recepción de la medida en el continente europeo: Reino Unido, Portugal, Suecia, Suiza y España. Finalmente revisaremos la forma en que América Latina ha dado los primeros pasos en la materia.

El segundo capítulo busca llevar a cabo una descripción de la aplicación del monitoreo telemático en nuestro país. La medida constituye una de las innovaciones más relevantes que trajo consigo la Ley $\mathrm{N}^{\circ} 20.603$ (promulgada el 13 de junio de 2012 y publicada el 27 del mismo mes y año). Así, se revisará el modo y ámbito de aplicación de la monitorización. De esta forma, al interior de esta nueva regulación la "pulsera electrónica" cumple una función de complemento y refuerzo a dos nuevos institutos sustitutivos de las penas privativas de libertad: la reclusión parcial y la libertad vigilada intensiva.

El tercer capítulo tiene por objeto analizar críticamente las finalidades de la medida. Este ejercicio se hará a la luz de la sociología del control y la economía política del castigo. Para dicho fin, en primer lugar, nos valdremos de los conceptos expuestos por Michel Foucault con la idea de describir la 
monitorización como un mecanismo de control estatal que actúa sobre el cuerpo del sujeto por medio de la vigilancia permanente. Además, mediante la obra del autor Pierre Bourdieu describiremos que aquel control y normalización se ejerce con el fin de imponer un mensaje simbólico de vigilancia permanente a los sujetos.

Finalmente, con Gilles Deleuze sostendremos que dicho mecanismo de vigilancia representa un dispositivo propio de las "sociedades de control", las que, en definitiva, se caracterizarían por la diseminación de la vigilancia en la sociedad.

Además, nos valdremos de los autores que de forma más perspicua han descrito la intervención penal y los mecanismos de control social por parte del Estado, en la actualidad (David Garland, Loïc Wacquant y Alessandro de Giorgi). Con esto, se describirá el nacimiento de la medida y su consolidación como una redefinición del papel del Estado, desde una concepción más ligada al bienestar, a una concepción vinculada directamente con la prevención, control, vigilancia y castigo.

\section{Historia y regulación comparada del monitoreo telemático}

\section{a) Estados Unidos}

Como ya hacíamos mención, el monitoreo telemático, o simplemente monitorización, surge en Estados Unidos en la década del 60. La doctrina ha identificado tres etapas en su evolución:

\section{i) Primera etapa:}

La primera fase de desarrollo de la medida se ubica entre principios de los años sesenta y mediados de la década de los setenta. Esta etapa se destaca por la invención y desarrollo del mecanismo/dispositivo (1964-1970) gracias al trabajo de un grupo de psicólogos experimentales de Harvard, dirigidos por el doctor Ralph Schwitzgebel. Estos científicos diseñaron un pequeño dispositivo llamado Behavior-Reinforcer (BT-R), el que tenía por objeto complementar la libertad condicional y la probation aplicadas a sujetos reincidentes peligrosos. ${ }^{1}$ Sin embargo, dicha medida no prosperó en el sistema norteamericano.

\section{ii) Segunda etapa:}

Esta segunda fase se encuentra entre mediados de los años setenta y 1983, año en que se instala el primer mecanismo de control electrónico comunitario en Florida. Dicho mecanismo, sin embargo, no cautivó el interés por parte de los operadores

\footnotetext{
1 Ardley, Jenny: The Theory, Develpment and Application of Electronic Monitoring in Britain. Internet Journal of Criminology, 2005, p. 2. También en Kilgore, James: Progress or More of the Same? Electronic Monitoring and Parole in the Age of Mass Incarceration, 2012, p. 5.
} 
Peña - Monitoreo telemático...

del sistema. En primer lugar, debido al insuficiente desarrollo de la tecnología. En efecto, era demasiado voluminoso, el campo de transmisión no superaba un cuarto de milla y el campo de recepción era de, aproximadamente, dos millas. ${ }^{2}$

\section{iii) Tercera etapa:}

Esta fase del desarrollo se destaca por el resurgimiento del interés en el monitoreo telemático producto de la acción de un juez de Albuquerque, Nuevo México, llamado Jack Love. Este juez, en 1983, tras la propuesta de un experto en electrónica llamado Michael Goss, impuso la primera sentencia de arresto domiciliario con control electrónico. ${ }^{3}$ Dicho juez, frustrado por la falta de alternativas al encarcelamiento, probó este mecanismo que se instalaba en el tobillo del sujeto. ${ }^{4}$ Posteriormente Love propuso al Departamento de Ejecución de Penas de Nuevo México la utilización de la monitorización para los sujetos condenados a prisión por conducir en estado de ebriedad y aquellos condenados por los delitos llamados "delitos de cuello blanco". Conjuntamente, el National Institute of Justice (Instituto Nacional de Justicia de Estados Unidos) apreció la viabilidad de la tecnología y estableció su aplicación con el arresto domiciliario. Finalmente, en 1984 se adoptó en Palm Beach, Florida, el primer programa de control electrónico. Su establecimiento tenía por objeto reducir el hacinamiento en las cárceles.

De este modo, comienza a ser aplicada la monitorización hasta nuestros días. El crecimiento exponencial en su aplicación resulta digno de destacar. En efecto, en 1988 había 2.277 condenados al control electrónico en diez estados de Estados Unidos. Diez años después, en 1998, se cuentan alrededor de 95.000 personas sujetas a monitorización. ${ }^{5}$ En la actualidad, pese a la insuficiencia de datos, se calcula que hasta junio de 2009 solo en Palm Beach, Florida, existían cerca de 143.000 personas sujetas a libertad condicional bajo monitoreo telemático. ${ }^{6}$ Por otro lado, como otra muestra del alcance de la medida, desde 1989, en el pequeño condado de Cook, Illinois, se ha aplicado la vigilancia electrónica a más de 250.000 personas. ${ }^{7}$ Esto demuestra la penetración del monitoreo telemático en el sistema penitenciario norteamericano.

En cuanto al ámbito de aplicación, en la vigilancia electrónica en Estados Unidos existen importantes diferencias regulatorias entre los estados federales. En algunos estados, y como pena principal, se utiliza el monitoreo telemático junto al arresto domiciliario. Conjuntamente, también se utiliza como alternativa o forma

2 Di Tella, Rafael and Schardgrodsky, Ernesto: Criminal Recidivism after Prison and Electronic Monitoring, 2012, p. 10. Nota al pie número 16.

${ }^{3}$ Ibid.

${ }^{4}$ Kilgore, James: Progress... (nota 1), p. 5.

${ }^{5}$ González Blanqué, Cristina: El control electrónico en el sistema penal, 2008, p. 22.

${ }^{6}$ U.S. Departament of Justice. Office of Justice Programs. National Institute of Justice: Electronic

Monitoring Reduces Recidivism, 2011, p. 1.

${ }^{7}$ Kilgore, James: Progress... (nota 1), p. 5. 
alternativa de ejecución de la pena de prisión incondicional. En otros estados, como medida adicional en el contexto de una suspensión condicional de la pena. Es por esta razón que se le considera entre las intermediate sanctions, es decir, se sitúa entre la ejecución de una pena y la suspensión condicional de la misma. ${ }^{8}$ No obstante lo anterior, en muchos estados se contempla el monitoreo telemático como una forma de vigilancia perpetua en contra de los sujetos que hayan sido condenados por crímenes de abuso y violencia sexual (luego de haberse cumplido la pena). ${ }^{9}$

Respecto de los sujetos a quienes se puede imponer vigilancia electrónica, son destinatarios: personas en libertad condicional o en periodo de prueba, personas condenadas por delitos sexuales, inmigrantes esperando sentencia, individuos involucrados en casos de violencia doméstica, personas declaradas culpables de conducir en estado de ebriedad u otros delitos relacionados con el tránsito, aquellos acusados de delitos menores como allanamientos o violaciones a ordenanzas municipales, y personas jóvenes que enfrentan cargos ante tribunales adolescentes. $^{10}$

\section{b) Europa y América Latina}

En Europa, el monitoreo telemático se encuentra actualmente en aplicación por países tanto de la tradición anglosajona como de la tradición continental. Así, la monitorización se encuentra vigente, entre otros países, en Inglaterra, Gales, Francia, Portugal, Alemania, España, Suiza, Suecia e, incluso, fuera de Europa, en Australia.

El primero de estos países ha introducido, desde 1988, los primeros programas piloto como una alternativa a la prisión preventiva y al hacinamiento carcelario (este llegaba a un total de 49.000 reclusos en el año 1987, 7.000 personas más de lo que el sistema podía soportar. El 20\% de ellos en prisión preventiva). ${ }^{11}$ Así, en 1991 se establece la Criminal Justice Act, ley que introduce la monitorización conjunta a los arrestos domiciliarios (sanciones comunitarias). Conjuntamente, en 1998, se establece la Crime and Disorder Act, por medio de la cual se introduce la aplicación del mecanismo para la libertad condicional (license condition). Posteriormente, en el año 2000, se dicta la Power of Criminal Courts (Sentencing $A c t$ ). Este incorpora las exclusion orders, sanciones que involucraban el alejamiento del condenado de ciertos lugares, en el contexto de sanciones de cumplimiento comunitario. ${ }^{12}$ Finalmente, en el año 2003 se dicta la Criminal Justice

\footnotetext{
${ }^{8}$ Iglesias, Miguel Ángel y Pérez, Juan Antonio: La pena de localización permanente y su seguimiento con medios de control electrónico, 2006, p. 1083.

9 Torres Rosell, Nuria: Libertad vigilada y seguimiento continuado de penados: contenido e implicaciones político criminales, 2012, p. 15.

${ }^{10}$ Kilgore, James: Progress... (nota 1), p. 1.

${ }^{11}$ Ardley, Jenny: The Theory, Develpment and Application... (nota 1), pp. 8-9.

12 Torres Rosell, Nuria: Libertad vigilada... (nota 9), 2012, p. 18.
} 
Peña - Monitoreo telemático...

Act. Esta ley es la que actualmente rige en materia de monitorización y sanciones de cumplimiento comunitario. El aporte más relevante de esta ley son las extended and indeterminate sentences (penas extendidas e indeterminadas) a delincuentes sexuales y violentos de alto riesgo. ${ }^{13}$

De forma paralela, en relación con las tecnologías utilizadas, en 2001 se introduce el sistema biométrico (reconocimiento por voz) para el control del arresto domiciliario y, finalmente, entre 2004 y 2006 se introduce la tecnología GPS para el seguimiento de la libertad condicional. ${ }^{14}$

Este sistema contemplaba la aplicación de la monitorización como apoyo a dos sanciones comunitarias, a saber: la Curfew Order (CO) y la Home Detention Curfew (HDC). La primera de ellas es una sanción comunitaria que puede ser reforzada con la vigilancia electrónica o con otras sanciones comunitarias o pecuniarias. Por su parte, la segunda, permite abandonar anticipadamente la prisión. $^{15}$

Estadísticamente, hasta el 2011 se habían monitoreado más de 700.000 casos y actualmente se monitorean cerca de 22.000. Esto convierte al Reino Unido en el programa de aplicación más extensiva, fuera de Estados Unidos. ${ }^{16}$

En Francia, las medidas que permiten la vigilancia electrónica fueron introducidas en un periodo de tres años. La primera de las leyes fue la $\mathrm{N}^{\circ} 2005$ 1549, la que permite la aplicación de un seguimiento continuado mediante dispositivos electrónicos a sujetos que representen un alto riesgo de reincidencia tras el cumplimiento de la sanción impuesta. Así, se permite la aplicación de la vigilancia electrónica al adulto condenado a una pena privativa de libertad igual o superior a siete años. Esta sanción permite determinar la localización espacial del sujeto por un periodo de dos años, prorrogable por otros dos periodos (dependiendo si la infracción es crimen o simple delito). ${ }^{17}$

En segundo lugar, la ley del 25 de febrero de 2008 introduce surveillance de sûreté (vigilancia de seguridad). Esta medida postpenitenciaria permite la vigilancia continuada del sujeto que ha sido condenado a una pena igual o superior a quince años de prisión. Bajo dicha vigilancia, el condenado debe cumplir determinadas obligaciones, entre las cuales se encuentra someterse a un régimen de vigilancia electrónica. ${ }^{18}$

\footnotetext{
${ }^{13}$ Ibid.

14 Ministerio de Justicia: Nueva Ley N¹8.216. Análisis de las modificaciones introducidas por la Ley 20.603. Material para capacitación, 2012, p. 104.

15 Ardley, Jenny: The Theory, Development and Application... (nota 1), pp. 4-14.

${ }^{16}$ Ministerio de Justicia: Nueva Ley No18.216 ... (nota 14), p. 104

17 Torres Rosell, Nuria: Libertad vigilada... (nota 9), 2012, p. 20.

${ }^{18}$ Ibid., p. 21.
} 
Finalmente, la Ley $\mathrm{N}^{\circ}$ 2010-242, del 10 de marzo de 2010, vino a confirmar el papel de la vigilancia electrónica. Esta ley, en su artículo 5, establece que si bien el condenado puede elegir la utilización de la vigilancia electrónica, este es advertido que de no aceptar dicho dispositivo o de incumplir las obligaciones, de aceptarlo, el sujeto puede ser internado en un centro sociomédico-judicial. ${ }^{19}$

En Suiza la vigilancia electrónica ha sido fácilmente aceptada en algunos cantones (por ejemplo, Ginebra, Basilea y Vaud, cuyas regulaciones no son idénticas), pero fundamentalmente rechazada en otros (por ejemplo, Zurich), por lo que solo se encuentra regulada a nivel local. ${ }^{20}$ En estos cantones se utiliza el monitoreo telemático como una forma de supervisión del arresto domiciliario por no más de doce meses. ${ }^{21}$

En Australia es posible diferenciar la aplicación de la vigilancia electrónica en tres fases: En primer lugar, previo a la sentencia (de uso provisional), como parte de la concesión de la libertad bajo fianza, para quienes solicitan asilo mientras sus solicitudes se están procesando y, finalmente, se utiliza cuando se dictan órdenes de restricción de acercarse a la víctima. En segundo lugar, al momento de la sentencia, el monitoreo electrónico puede imponerse bajo ciertas restricciones de libertad que se imponen al condenado y como una forma de prevención de acercamiento a la víctima del delito por el cual es condenado. Finalmente, se puede imponer luego de haber cumplido con la pena de prisión, cuando se produce una liberación anticipada del recluso. ${ }^{22}$

Portugal, por otro lado, ha establecido el sistema de vigilancia electrónica como mecanismo para controlar el arresto domiciliario de imputados y condenados, el seguimiento de la libertad condicional y los delitos relacionados con la violencia intrafamiliar tanto para condenados como para imputados. ${ }^{23}$

En Alemania, la entrada en vigor el 1 de enero de 2011 de la Gesetz zur Neuordnung des Rechts der Sicherungsverwabrung und zu begleitenden Regelungen, aprobada el 22 de diciembre de 2010, permitió la vigilancia permanente sobre los sujetos por medio de mecanismos electrónicos. No obstante, el monitoreo electrónico ya era ocupado en el ámbito de medidas cautelares y de la probation, es decir, siempre como una forma de controlar la permanencia o ausencia del sujeto en su domicilio, utilizando para ello sistemas estáticos de radiofrecuencia. La introducción en el sistema jurídico alemán de la vigilancia continuada por medio del sistema GPS se debe a la sentencia del Tribunal Europeo de Derechos

\footnotetext{
${ }^{19}$ Ibid., p. 22.

20 Killias, Martin; Gillie'Ron, Gwladys; Kissling, Izumi, and Villetaz, Patrice: Community Service Versus Electronic Monitoring-What Works Better? 2010, pp. 1-4.

${ }^{21}$ Weber, Jonas and Nett, Jachen: COST Action IS 1106: Offender Supervision in Europe Country Report for Switzerland, 2011, p. 13.

22 Black, Matt and Smith, Russell G.: Electronic Monitoring in the Criminal Justice System, 2003, pp. 3-4.

${ }^{23}$ Ministerio de Justicia: Nueva Ley $N^{\circ} 18.216 \ldots$ (nota 14), p. 105.
} 
Peña - Monitoreo telemático...

Humanos, del 17 de diciembre de 2009, el cual falló en contra de la aplicación retroactiva de la Sicherungsverwahrung (custodia de seguridad). Esta medida postsancionatoria permitía la internación de delincuentes sexuales y considerados peligrosos con posterioridad al cumplimiento de la pena de prisión. Dicha resolución del tribunal permitió la liberación de cientos de sujetos considerados peligrosos. De este modo, se estableció la posibilidad de un seguimiento continuado mediante un dispositivo GPS.

Las hipótesis en las que se aplica la monitorización son dos: En primer lugar, a los sujetos que hayan finalizado la ejecución de una pena de prisión superior a tres años en delitos contra la vida, integridad física, libertad y libertad sexual. En segundo lugar, se aplica a los sujetos que han terminado de cumplir una medida de seguridad a los que previamente se les aplicaba la custodia de seguridad. ${ }^{24}$

En Suecia, por su parte, es uno de los países en Europa que ha utilizado hace más años el monitoreo telemático (puesto a prueba en 1994 y oficialmente utilizado desde 1996). En cuanto a su ámbito de aplicación, la vigilancia electrónica se aplica en los siguientes casos: en primer lugar, es utilizado como una forma de controlar las condiciones impuestas a un sujeto a que remite la pena de prisión de corta duración (especialmente, pero no exclusivamente, se dirige a quienes resulten condenados por conducir en estado de ebriedad). En segundo lugar, se utiliza en los casos de libertad anticipada. Existen, a su vez, proyectos de aplicación en materia de delincuencia juvenil (15 a 18 años) y órdenes de alejamiento de víctimas. ${ }^{25}$

Finalmente, en España se ha introducido, en primer lugar, mediante el Reglamento Penitenciario de 1996. El Reglamento establece, en su artículo 86.4, una nueva forma de cumplimiento del régimen abierto que permite a los internos de tercer grado sometidos a los regímenes de semilibertad, sustituir la permanencia en el centro penitenciario con vigilancia electrónica durante ocho horas, o pernoctar en el mismo. En segundo lugar, también se establece en el ámbito de la violencia doméstica. El 2003 la LO 15/2003 introduce la posibilidad de aplicar la monitorización como medio de control junto a la pena de alejamiento del artículo 48 del Código Penal español (por medio de la pena de privación de derecho de residir o acudir a un lugar determinado). Finalmente, mediante la misma ley, también puede imponerse la vigilancia electrónica como un mecanismo de control de la pena llamada localización permanente, regulada en los artículos 33 a 35 del Código Penal español, solamente aplicada a las infracciones constitutivas de falta. ${ }^{26}$

\footnotetext{
${ }^{24}$ Torres Rosell, Nuria: Libertad vigilada... (nota 9), pp. 23-26.

25 Nellis, Mike and Vanhaelemeesch, Delphine: Conference Report. Towards a Gold Standard in The Practice of Electronic Monitorin, 2012, pp. 15-16.

${ }^{26}$ Iglesias, Miguel Ángel y Pérez, Juan Antonio: La pena de localización permanente... (nota 8), pp. 1071-1086.
} 
En cuanto a América Latina, el panorama es similar. En efecto, se ha avanzado en la adopción de tecnologías de control a distancia en países como Argentina, Colombia, Panamá y Uruguay.

En Argentina, la provincia de Buenos Aires avanzó en su aplicación mediante un plan piloto desde 1997. El dispositivo utilizado se trataba de un anillo ubicado en la muñeca o en el tobillo, que permitía cautelar al imputado mientras el proceso judicial aún tenía lugar, es decir, durante el tiempo en que el sujeto esperaba su condena. Dicha finalidad fue atribuida, fundamentalmente, para combatir el hacinamiento carcelario, toda vez que cerca del $85 \%$ de la población privada de libertad se encontraba en dicha condición a causa de esta medida cautelar. El principal problema era su escasa cobertura, pues solo era posible aplicar el mecanismo a trescientas personas. En la actualidad, dicho programa piloto fue cerrado, por lo que este país no cuenta con monitoreo telemático. ${ }^{27}$

Por su parte, en Colombia se estableció formalmente el monitoreo telemático según la Ley $\mathrm{N}^{\circ}$ 1142, desde el 2007. Su implementación se entregó a un reglamento mediante el Decreto $\mathrm{N}^{\circ} 177$ en el 2008, el que establece los requisitos para imponer la vigilancia electrónica. Dicho sistema de monitorización es utilizado como medida sustitutiva a la pena de prisión y su aplicación la determina el juez de ejecución de las penas a quienes hayan sido sancionados por delitos de escasa y mediana gravedad. ${ }^{28}$ El 2010 se produce su implementación definitiva a todo el territorio del país. ${ }^{29}$ Contempla, a su vez, las tecnologías de GPS pasivo, GPS activo y reconocimiento de voz. ${ }^{30}$

En Panamá, mediante la resolución $\mathrm{N}^{\circ} 46$ emitida por el Ministerio Público, el 29 de diciembre de 2009 se introduce permanentemente el uso de brazalete electrónico para garantizar el cumplimiento de las medidas cautelares. Tal mecanismo se plantea como un sistema de seguimiento permanente y se encuentra bajo la supervisión de la Dirección de Asistencia y Coordinación Penitenciaria de la Procuraduría General de la Nación. ${ }^{31}$

En el caso de Uruguay, la Corte Suprema de Justicia habilitó el uso de estos sistemas en noviembre del 2003 solo para los imputados primarios por delitos

\footnotetext{
${ }^{27}$ Di Tella, Rafael and Schardgrodsky, Ernesto: Criminal Recidivism... (nota 2), 2012, pp. 10-14.

${ }^{28}$ Esta medida puede ser impuesta mediante el cumplimiento de los siguientes requisitos: que el imputado no tenga otros antecedentes penales, que suscriba una acta de compromiso, que presente caución que garantice el cumplimiento de las restricciones a la libertad que implica el mecanismo y, finalmente, que repare los perjuicios ocasionados a la víctima del hecho punible.

${ }^{29}$ Ministerio de Justicia: Nueva Ley $N^{\circ} 18.216 \ldots$ (nota 14), pp. 106-108. También en Hernández Jiménez, Norberto: Los sistemas de vigilancia electrónica como sustitutivos de la prisión bajo una perspectiva analitico-económica del derecho, 2012, pp. 1-7.

30 Ibid., p. 6.

31 Procuraduría general de la nación: Resolución $N^{\circ}$ 46: Que implementa de manera permanente el Programa de Sistema de Localización Telemática a través del uso del Brazalete Electrónico de Monitoreo para garantizar el cumplimiento de Medidas Cautelares, 2009, pp. 1-3.
} 
leves, hurtos pequeños, homicidios culposos en accidentes de tránsito, y solo por medio de resolución judicial. Actualmente el Ministerio del Interior se encuentra en proceso de licitación de la compra o alquiler de pulseras electrónicas para presos que sean enviados a prisión domiciliaria. ${ }^{32}$

\section{c) Síntesis}

Luego de exponer las diversas regulaciones que presenta el derecho comparado en la materia, es posible extraer ciertas características generales relativas a la utilización de la monitorización, finalidad, tecnologias ocupadas, procedimientos de aplicación, contexto de introducción y beneficios propios de la medida.

En primer lugar, respecto del uso del monitoreo telemático, cabe mencionar que constituye un mecanismo de vigilancia que se instala en el cuerpo del sujeto (en la mayoría de los casos), con el objeto de verificar la ubicación espacio-temporal del mismo. De este modo es posible controlar el cumplimiento de las distintas medidas que apoya, a saber, medidas cautelares, penas propiamente tales $\mathrm{y}$, finalmente, la pena de prisión.

En segundo lugar, en relación con la finalidad de la medida, la mayoría de los países que han instalado la vigilancia electrónica lo han hecho como respuesta al creciente hacinamiento en las cárceles. A esto se suma la posibilidad de mantener el control sobre los sujetos a un menor costo. ${ }^{33}$ En efecto, se estima que en Estados Unidos el costo de la monitorización es seis veces menor que la prisión. ${ }^{34}$ De este modo, el ahorro en la construcción de nuevas cárceles y en la vigilancia de los sujetos es asumido por este nuevo mecanismo como una virtud que motiva su utilización. ${ }^{35}$

En tercer lugar, las tecnologias utilizadas han sido tres: monitorización por radiofrecuencia, dispositivo no removible que se instala en el tobillo del sujeto. Este dispositivo envía señales a una unidad básica instalada en el domicilio de la persona, el que a su vez envía información al centro de monitoreo. En segundo lugar, se encuentra el monitoreo biométrico, mecanismo de reconocimiento de voz, instalado en una computadora, que tiene por función llamar aleatoriamente al domicilio del sujeto con el fin de verificar la presencia del mismo. Finalmente, se utiliza el monitoreo satelital o GPS, mediante el cual se sigue al sujeto a todos los lugares donde se dirige, por medio de la emisión de señales satelitales al centro de

\footnotetext{
32 Ministerio de Justicia: Nueva Ley $N^{\circ} 18.216 \ldots$ (nota 14), p. 110.

33 No obstante existir distintas categorías de monitoreo telemático, entre las cuales destaca la radiofrecuencia, el sistema pasivo de GPS y el sistema activo de GPS, el más caro de ellos es claramente inferior al costo de la prisión.

34 U.S. Departament of Justice. Office of Justice Programs. National Institute of Justice: Electronic... (nota 6).

${ }^{35}$ Martinovic, Marietta: The punitiveness of electronically monitores community based programs, 2002, p. 3.
} 
REJ - Revista de Estudios de la Justicia - No 18 - Año 2013

monitoreo. ${ }^{36}$ En este último caso, la extracción de los datos es ilimitada. Constituye un mecanismo ideal para el cumplimiento de las zonas de exclusión. ${ }^{37}$

En cuarto lugar, dentro de los procedimientos de aplicación, cabe consignar que todos los países comenzaron la aplicación por medio de programas piloto. Otros, por su parte, ya han alcanzado la aplicación completa de la medida (Estados Unidos, Reino Unido, Panamá, Colombia).

En quinto lugar, el contexto dentro de cual se aplica la medida permite sostener la existencia de una diferencia entre los países de tradición anglosajona y aquellos de tradición continental. Así, los primeros no han implementado el sistema por medio de una regulación rigurosa y pormenorizada, sino que lo han establecido como una atribución judicial al dictar sentencia. Su regulación queda sujeta a las disposiciones del servicio penitenciario respectivo. Por su parte, en los países de tradición continental existen normas y leyes que introducen la medida y reglamentos administrativos que regulan su aplicación. ${ }^{38}$

Finalmente, producto del carácter permanente de la vigilancia que impone, se ha llegado a estimar que uno de sus mayores beneficios sería la eficacia en la normalización de la conducta. Se ha estimado que permitiría reducir la reincidencia y, por tanto, potenciar la reinserción en la comunidad. ${ }^{39}$ El problema de esta afirmación reside en que, como sostiene la mayoría de la doctrina en la materia, ninguno de los estudios que aborda la efectividad de la medida resulta convincente, especialmente por los errores metodológicos cometidos en su elaboración. ${ }^{40} \mathrm{La}$ única excepción a este respecto es el caso de los delincuentes sexuales, sobre quienes existe un estudio que establece la disminución de las infracciones a la ley con posterioridad a la aplicación del monitoreo. Sin embargo, en esta clase de delincuentes solo resulta efectivo para aquellos de más alto riesgo (según una concepción actuarialista). ${ }^{41}$ Además, el hecho de que dicha tesis solo haya sido sostenida por un trabajo en la materia, no permite una afirmación tan

\footnotetext{
36 Ibid., p. 106.

37 Office of Program Policy Analisys and Goverment Accountability an Office of the Florida Legislature: Electronic monitoring should be better targeted to the most dangerous offenders, 2005, p. 2.

${ }^{38}$ Ministerio de Justicia: Nueva Ley No 18.216... (nota 14), p. 103.

39 International Association of Chiefs of Police and American Probation and Parole Association: Tracking Sex Offenders with Electronic Monitoring Technology: Implications and Practical Uses for Law Enforcement, 2008, pp. 6-8.

40 Renzema, Marc y Mayo-Wilson, Evan: Can electronic monitoring reduce crime for moderate to high-risk offenders? 2005. Esta conclusión también ha sido sostenida por la International Association of Chiefs of Police and American Probation and Parole Association: Tracking Sex... (nota 39), p. 8, quienes, a pesar de su apoyo a la medida, reconocen este aspecto como una de las debilidades del sistema. Reconocen también la ausencia de resultados comparativos del estudio realizado por la Office of Program Policy Analisys and Goverment Accountability an Office of the Florida Legislatura: Electronic monitoring... (nota 37), p. 4.

${ }^{41}$ V. Gies, Stephen; et al. Monitoring High-Risk Sex Offenders With GPS Technology: An Evaluation of the California Supervision Program, Final Report. Office of Research and Evaluation National Institute of Justice, 2012, p. 101.
} 
Peña - Monitoreo telemático...

categórica. ${ }^{42}$ En relación con los delincuentes juveniles, se ha destacado que dicho mecanismo de vigilancia puede provocar un aumento en su comportamiento delictivo. $^{43}$

Previo al análisis de la medida en nuestro país, cabe resaltar el supuesto efecto bumanizador que se le atribuye a la medida. Sobre este respecto nos pronunciaremos en los siguientes capítulos. Sostendremos que no obstante permitir que los sujetos se ubiquen fuera del alcance de la prisión, la medida esconde efectos y finalidades ulteriores relacionadas con la extensión del control y vigilancia estatal sobre la sociedad.

\section{Aplicación en Chile}

\section{a) Introducción del monitoreo telemático en Chile}

El monitoreo telemático ingresa al sistema jurídico nacional por medio de la dictación de la Ley $\mathrm{N}^{\circ}$ 20.603, promulgada el 6 de junio de 2012 y publicada el 27 de junio del mismo año. Esta nueva regulación tiene por objeto modificar la Ley $\mathrm{N}^{\mathrm{o}}$ 18.216, legislación que regulaba las medidas alternativas a la privación de libertad. En efecto, la Ley $\mathrm{N}^{\circ} 20.603$ no solo modifica en algunos aspectos las medidas ya existentes, sino también introduce algunas nuevas, a saber: libertad vigilada intensiva, expulsión, en el caso del artículo 34 de la ley, y finalmente, prestación de servicios en beneficio de la comunidad. De este modo, el catálogo de medidas -que desde ahora pasan a llamarse sustitutivas a la privación de libertad- ${ }^{44}$ es el siguiente:

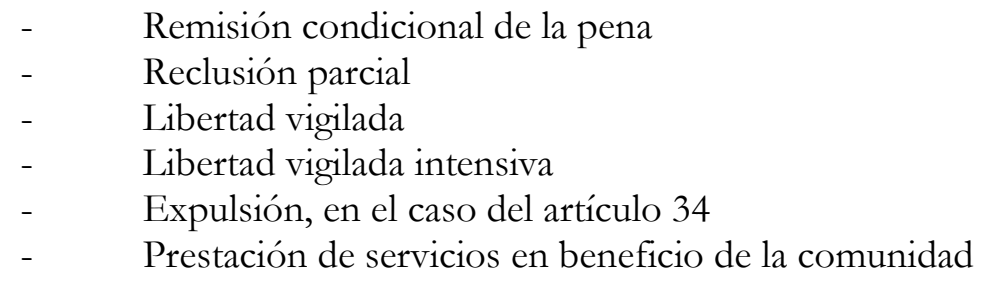

En cuanto a los fines que presenta la introducción de la medida en Chile, la historia de la ley da muestras de distintas motivaciones del legislador en su establecimiento:

\footnotetext{
42 Payne, Brian and Demichele, Mathew: Electronic supervision for sex offenders: Implications for workload, supervision goals, versatility, and policy making, 2010, pp. 276-281.

${ }^{43}$ Lipsey, Mark; Howell, James; Kelly, Marion; Chapman, Gabrielle; Carver, Darin: Improving the effectiveness of juvenile justice programs. A new perspective on evidence based practice, 2010, p. 17.

${ }_{44}$ Durante la discusión parlamentaria, en la discusión general, los representantes del ejecutivo sostuvieron que el cambio de denominación de las medidas obedecía a que estas eran más bien "penas para el condenado y no medidas o beneficios". Historia de la Ley, Ley No 20.603, p. 64. Disponible en http:// wmw.leychile.cl/Navegar?idNorma $=1040510$.
} 
El mensaje presidencial que enviaba el proyecto de ley para su discusión en la Cámara de Diputados contemplaba dos finalidades: una efectiva reinserción del sujeto y, en especial, mantener el carácter de penas sustitutivas de las medidas que se introducen, estableciendo para su efectividad mayores y mejores mecanismos de control en la ejecución de la sanción impuesta. Así, sería posible "[hacer] de este sistema un modelo de control asimilable a la prisión, en cuanto a su real control sobre la población sujeta al mismo". ${ }^{45}$

Luego del mensaje se establecieron indicaciones que tuvieron por objeto profundizar el carácter punitivo de estas medidas mediante políticas de seguridad ciudadana, las que se basaban, para su implementación, en los "índices de temor" y "encuestas de victimización". De este modo se pretendía terminar con el "flanco de impunidad" que constituían las medidas alternativas. ${ }^{46}$ Se buscaba "robustecer el sistema de alternativas a la prisión" y transformarlo "en un mecanismo de sanción que opere de manera eficaz y efectiva en el control de la delincuencia primeriza y cuyos objetivos se centren en evitar la reincidencia delictual y dar protección a las victimas". ${ }^{47}$

Adicionalmente se establecieron otras finalidades, como la imposición de penas inteligentes y el uso de nuevas tecnologías para controlar su cumplimiento. ${ }^{48}$ De acuerdo con la primera, se buscaba imponer un "castigo enérgico, pero resocializador" a los delincuentes primerizos y así lograr un "uso eficiente de los recursos". Por su parte, la segunda de estas finalidades buscaba que "las personas condenadas [supieran] que efectivamente están siendo controladas, de manera que cualquier acción que atente contra el régimen de sanción impuesto será detectada e informada al tribunal". En consecuencia, se buscaba que las medidas sustitutivas permitieran al delincuente primerizo reinsertarse en la sociedad por medio de una sanción acorde a su escasa peligrosidad y así evitar un efecto de "infección" por medio del contacto con otros delincuentes en la prisión. Sin embargo, pese al reconocimiento de su escasa peligrosidad, la ley establece medidas de vigilancia electrónica con el objeto de establecer un control permanente de la conducta del individuo.

Conjuntamente, surge el reconocimiento del problema del encarcelamiento masivo y el hacinamiento de las cárceles en Chile, cuestión que debía ser solucionada permitiendo el acceso a regímenes de semilibertad. ${ }^{49}$

\footnotetext{
${ }^{45}$ Ibid., p. 6

46 Indicación sustitutiva del Ejecutivo. Ibid., p. 18.

47 Ibid., p. 19.

48 Ibid., p. 67.

${ }^{49}$ En efecto, Chile ocupa el lugar número 40 en el mundo en relación con la tasa de privación de libertad por cada 100.000 habitantes, con 296, superando a países como México, Inglaterra, España, Italia, Alemania, Francia, etc. Por su parte, en América Latina Chile ubica la segunda posición en dicha tasa, solo siendo superado por Guyana Francesa. En cuanto al hacinamiento carcelario, nuestro país presenta en general 36,4\% de sobrepoblación, llegando, en algunos sectores, a 57,8\%. Datos de Ministerio de Justicia: Nueva Ley $N^{\circ} 18.216 \ldots$ (nota 14), pp. 15-16.
} 
Se suma a lo anterior el contagio criminal del condenado primario. Así, se ha entendido que resulta más perjudicial socialmente sancionar con privación de libertad a aquellos sujetos cuyos delitos merezcan penas de corta duración. En términos de prevención especial positiva y de riesgos para la comunidad, resulta mucho más efectivo mantener al sujeto en libertad.

Por último, también se ha estimado necesario una mayor participación de la comunidad en la gestión de la justicia penal. ${ }^{50}$

A modo de resumen, a lo largo de la tramitación de la ley se presentaron como finalidades las siguientes: reinserción, efectividad, fin a la impunidad, uso de nuevas tecnologias y penas inteligentes, remedio al bacinamiento y encarcelamiento masivo, prevención del contagio criminal y participación comunitaria. ${ }^{51}$

Estos objetivos resultan acordes con los resultados del debate académico sobre la llamada "crisis de la prisión". Dicha crisis se origina por variados factores, entre los cuales se encuentran: en primer lugar, la deslegitimación de la cárcel como mecanismo de control social. El carácter disciplinario de la prisión, su posibilidad de controlar, normalizar y corregir toda conducta individual, han producido innumerables objeciones en la segunda mitad del siglo XX. ${ }^{52}$

En segundo lugar, se ha sostenido el compromiso de clase y de raza que implica. ${ }^{53}$ La formación de verdaderos guetos al interior de las prisiones ha generado críticas a esta forma de sanción.

En tercer lugar, el carácter desocializador de dicha medida. No es casualidad que gran parte de los cuestionamientos que han comenzado a surgir durante el siglo XX versan sobre el fracaso resocializador de la prisión. En efecto, ya no sería posible concebir a la cárcel como instrumento funcional al hombre en sociedad, sino todo lo contrario. ${ }^{54}$ Esto se ha manifestado en la generación de verdaderas subculturas criminales al interior de las prisiones, cuestión que extrae al sujeto de los cánones culturales que la sociedad establece, imposibilitando su resocialización.

\footnotetext{
50 Principio contenido en las Reglas Mínimas de las Naciones Unidas sobre las Medidas no Privativas de libertad, aprobadas por la Asamblea General de la ONU, el 14 de diciembre de 1990, mediante resolución $\mathrm{N}^{\circ} 45 / 110$.

${ }^{51}$ Llama la atención, en este sentido, el importante número de finalidades que se han atribuido a esta ley. Esto se debe, entre otras razones, a que el proyecto de ley fue discutido durante distintos gobiernos, con ciertas diferencias ideológicas (aunque no fundamentales) en sus políticas de persecución penal. En efecto, el mensaje presidencial fue enviado durante el gobierno de Michelle Bachelet (31 de marzo de 2008) y fue publicada el 27 de junio de 2012, durante el gobierno de Sebastián Piñera.

${ }^{52}$ Foucault, Michel: Vigilar y Castigar: el Nacimiento de la prisión, 2000.

53 Wacquant, Loïc: Castigar a los pobres: El gobierno neoliberal de la inseguridad social, 2010, pp. 281-300.

${ }^{54}$ Cesano, José Daniel: "De la crítica a la cárcel a la crítica a las alternativas". Boletín mexicano de derecho comparado, 2003, p. 3.
} 
En este contexto surgió la antigua Ley $\mathrm{N}^{0}$ 18.216, que contemplaba medidas alternativas a la privación de libertad; y la actual Ley $\mathrm{N}^{\circ}$ 20.603, que introduce medidas sustitutivas a la privación de libertad. Actualmente dichas medidas se encuentran vinculadas directamente al cumplimiento de las sanciones en el medio libre, mediante el apoyo comunitario. Así surge el monitoreo telemático, como una medida que apoya, mediante la vigilancia, la imposición de algunas de las sanciones que establece la ley.

\section{b) Ámbito de aplicación}

El artículo 23 bis de la Ley $N^{\circ} 20.603$ establece: "Se entenderá por monitoreo telemático toda supervisión por medios tecnológicos de las penas establecidas por esta ley". En este sentido, se desprende de la ley que la monitorización constituye una medida que busca asegurar el cumplimiento de las medidas sustitutivas establecidas en la nueva regulación por medio de control o supervisión electrónica. En consecuencia, no es pena por sí misma, sino que un mecanismo de control de algunas de las sanciones contenidas en la ley.

El inciso segundo del mismo artículo establece: "Dicho control podrá ser utilizado para la supervisión de las penas de reclusión parcial y de libertad vigilada intensiva". Y el artículo 23 bis A, dispone: "tratándose del régimen de pena mixta, previsto en el artículo 33 de esta ley, la supervisión a través de monitoreo telemático será obligatoria durante todo el período de la libertad vigilada intensiva". En consecuencia, el monitoreo telemático posee un ámbito acotado de medidas en las que se aplica. En efecto, tal como sostienen las disposiciones citadas, solo se aplica en tres casos: reclusión parcial, libertad vigilada intensiva y libertad vigilada intensiva por aplicación de pena mixta.

Es necesario explicar, por cada medida, los casos en los que procede la aplicación del monitoreo telemático.

\section{i) Reclusión parcial}

Mediante la modificación de lo que anteriormente se regulaba como "reclusión nocturna", cambió el lugar, horario y días en los cuales se puede dar cumplimiento a dicha medida. Así, se establecieron tres modalidades de ejecución:

- reclusión diurna: encierro en el domicilio del condenado, durante un lapso de 8 horas diurnas y continuas, las que se fijarán entre las 8 y 22 horas.

- reclusión nocturna: encierro en el domicilio o establecimientos especiales, entre las 22 horas de un día y las 6 horas del día siguiente. 
Peña - Monitoreo telemático...

- reclusión de fin de semana: encierro en el domicilio del condenado o en establecimientos especiales, entre las 22 horas del día viernes y las 6 horas del día lunes siguiente. ${ }^{55}$

De este modo, resultaba necesario, con la finalidad de "entregar credibilidad" a la pena sustitutiva, contar con un tipo de supervisión de este tipo. Así lo establece el artículo séptimo de la ley, resultando solamente improcedente en los casos en los que Gendarmería de Chile informe desfavorablemente la factibilidad técnica de su imposición. Al interior de esta medida, la monitorización procederá en todos los delitos contemplados para ella.

\section{ii) Libertad vigilada intensiva}

De acuerdo con el artículo 14 de la ley, esta medida consiste en someter al penado a un régimen de libertad a prueba, que tenderá a su reinserción social mediante una intervención individualizada bajo la vigilancia y orientación permanentes de un delegado de Gendarmería de Chile. Esta sanción (junto a la libertad vigilada), a diferencia del resto de las medidas que establece la ley, es la única que contempla un proceso de intervención individualizado. Sin embargo, solo la libertad vigilada intensiva contempla la supervisión por medio de la vigilancia electrónica. Por su parte, el inciso tercero del artículo 23 bis señala que tratándose de la libertad vigilada intensiva, el monitoreo solo se utilizará para controlar los delitos contemplados en la letra b) del artículo 15 de la ley. Estos son:

- delitos cometidos en contexto de violencia intrafamiliar ${ }^{56}$

- delitos contra la indemnidad sexuap ${ }^{7}$

Por lo tanto, no cualquier condenado a libertad vigilada intensiva puede ser sujeto a monitorización, sino solo aquellos que hayan incurrido en los delitos mencionados.

Para imponer este tipo de vigilancia, sostiene el mismo inciso, el tribunal tendrá en cuenta las circunstancias de comisión del delito y especialmente las necesidades de protección de la víctima. Así, el monitoreo telemático se impondrá cuando el cumplimiento de las condiciones establecidas por la medida, y con

\footnotetext{
${ }^{55}$ Ministerio de Justicia: Nueva Ley $N^{\circ} 18.216 \ldots$ (nota 14), p. 35.

${ }^{56}$ Dentro estos delitos se encuentran: homicidio simple y calificado (Art. $391 \mathrm{CP}$ ), amenazas (Arts. 296 y 297 CP), parricidio (Art. 390 CP), castración (Art. 395 CP), otras mutilaciones (Art. 396 CP) y lesiones graves y menos graves (Arts. 396, 397 y 398 CP).

57 Dentro de estos delitos se encuentran: estupro (Art. $363 \mathrm{CP}$ ), abuso sexual agravado por la introducción de objetos (Art. $365 \mathrm{CP}$ ), abuso sexual (Art. $366 \mathrm{CP}$ ), abuso sexual respecto de persona menor de 14 años (Arts. 366 bis y 366 quáter CP), participación en la producción de material pornográfico en que hayan sido utilizados menores de 18 años (Art. 366 quinquies), facilitación o promoción de la prostitución de menores de edad (Art. $367 \mathrm{CP}$ ), obtención de servicios sexuales de menor de 18 años y mayor de 14 años (Art. 367 ter $\mathrm{CP}$ ) y tráfico de personas (Art. 411 bis CP).
} 
REJ - Revista de Estudios de la Justicia - No 18 - Año 2013

motivo de la protección de la víctima del delito y de la reinserción del condenado, necesiten de verificación por medio de vigilancia.

\section{iii) Libertad vigilada intensiva por aplicación de pena mixta}

La pena mixta es un mecanismo que permite que las personas privadas de libertad, bajo ciertos requisitos, puedan interrumpir su cumplimiento sustituyéndose por el régimen de libertad vigilada intensiva. De este modo, es posible un egreso anticipado al cumplimiento formal de la pena privativa de libertad. En estos casos se debe imponer la vigilancia por medio del monitoreo electrónico de manera obligatoria (Art. 23 bis A).

Una de las innovaciones que trae esta ley es la aplicación del monitoreo telemático para las víctimas. Sin embargo, dicha labor de vigilancia solo es posible aplicarla en los casos que es procedente para la libertad vigilada intensiva (v. gr., ciertos delitos sexuales y delitos cometidos en el contexto de violencia intrafamiliar). Sin embargo, en este caso se aplica el monitoreo telemático atendiendo a las circunstancias de comisión del delito y a las necesidades de protección de la víctima, debiendo presentar su consentimiento de forma previa.

En definitiva, los requisitos para la procedencia en la aplicación de la vigilancia electrónica son los siguientes:

- Que se encuentre dentro de las tres hipótesis de su ámbito de aplicación

- Que exista un informe de factibilidad técnica favorable

- Que se decrete por resolución del tribunal

Finalmente, sostiene el inciso sexto del artículo 23 bis que el monitoreo telemático se aplicará por un plazo igual al de la duración de la medida sustitutiva que se impusiere.

\section{c) Excurso crítico en torno a las finalidades de la Ley $\mathrm{N}^{\circ} 20.603$ y el monitoreo telemático}

Las medidas alternativas a la privación de libertad (de la Ley $\mathrm{N}^{\circ}$ 18.216) surgen, como fue referido, en un contexto de crisis de la prisión. En efecto, durante el siglo XX el carácter "humanizador" de la cárcel (propio de los siglos XVII y XVIII), como forma de legitimación de esta, comienza a perder terreno.

Así, el control totalizante de la prisión sobre los cuerpos de los sujetos y sus mecanismos de vigilancia y normalización generan el inicio de un proceso de cuestionamiento a la institución durante la segunda mitad del siglo XX. Por otro lado, el carácter discriminatorio de su aplicación, la desocialización que produce en los sujetos, el factor de iniciación (o infección) en las carreras delictivas que produce en los condenados primerizos, el atentado de la reclusión a las familias, el hacinamiento carcelario y el cuestionamiento a la función resocializadora de dicha sanción (considerada 
Peña - Monitoreo telemático...

una verdadera "ideología del tratamiento") ${ }^{58}$ fueron los factores que dieron origen a estas medidas alternativas.

En este contexto, Chile ha sido un receptor de la discusión académica e institucional que ha surgido en torno a la crisis de la prisión y al contexto actual de la reclusión. De esta forma surge la Ley $\mathrm{N}^{\mathrm{o}} 18.216$ y aquella que la modifica, la Ley $\mathrm{N}^{\circ}$ 20.603, que establece medidas sustitutivas a las penas privativas de libertad. Sin embargo, si bien los fines que establece dicha ley resultan acordes a las críticas que se han venido elaborando a la prisión, la introducción del monitoreo telemático permite extraer conclusiones que evidencian finalidades ulteriores a las que ya han sido mencionadas y que serán relevantes cuando se analice la medida desde la sociología del control y del castigo.

En primer lugar, desde un punto de vista del lógico, resulta complejo entender la adición del monitoreo telemático a las medidas sustitutivas a la privación de libertad. Si el Estado, por medio de estos mecanismos, concede un espacio de libertad a los sujetos que han cometido delitos, resulta paradójico que intente insertar un mecanismo que limite dicha libertad. En efecto, tal como lo establece la propia ley, la vigilancia electrónica no es una pena por sí misma, sino que un mecanismo de control de algunas sanciones contenidas en la ley. Desde este punto de vista, resulta contraintuitiva una medida que introduce un mayor ámbito de control de los sujetos, si a estos previamente se les ha concedido este espacio de libertad. Esto muestra que los fines buscados mediante la ley no son, sin más, evitar el encarcelamiento de los sujetos (y, por tanto, otorgarles espacios de libertad), sino más bien introducir mecanismos de vigilancia en espacios fuera del alcance de la cárcel.

En segundo lugar, uno de los cuestionamientos de la doctrina a las penas privativas de libertad es la posibilidad de generar un efecto de infección a aquellos sujetos que no resultan de peligro para los fines preventivo-especiales de la sanción. Así, sería más perjudicial que aquellos individuos se sometan a una pena privativa de libertad por un corto tiempo, a que sean puestos en libertad. En este sentido, si los sujetos a los cuales se impone la reclusión parcial o la libertad vigilada intensiva no les resulta adecuado imponerles una medida que les prive de libertad (precisamente, porque no son peligrosos), resulta extraño establecer un control permanente sobre ellos. Es por esta razón que podría pensarse que, adicionalmente a evitar el efecto infeccioso de las cárceles, la medida busca introducir espacios de control adicionales a sujetos que se encuentran fuera del alcance de la cárcel.

Finalmente, es posible concluir que la creación de la libertad vigilada intensiva solo tendría, como consecuencia, la generación, al interior de la antigua libertad vigilada, de un ámbito dentro del cual se pudiera imponer un mayor

\footnotetext{
${ }^{58}$ Cesano, José Daniel: "De la crítica...” (nota 54), pp. 4-5.
} 
REJ - Revista de Estudios de la Justicia - No 18 - Año 2013

control sobre el sujeto. ${ }^{59}$ En efecto, de acuerdo con el artículo 15 de la Ley $\mathrm{N}^{\circ} 18.216$, se establecería sobre el sujeto la libertad vigilada cuando la pena que se le impusiera al sujeto no fuere superior a 5 años ni inferior a 2 años de privación de libertad. Con la nueva ley, dicho margen se dividió entre la libertad vigilada y la libertad vigilada intensiva. Así, la primera se impondrá cuando el sujeto sea condenado a una pena que no supere los 3 años de privación de libertad y no sea inferior a 2 años. En tanto, la segunda se impondrá cuando la pena no supere los 5 años ni sea inferior a 3 años de privación de libertad. Si a esto sumamos la posibilidad, solo contemplada en la libertad vigilada intensiva, de imponer la vigilancia electrónica, es posible concluir que, en ámbitos donde antes solo se imponía la libertad vigilada, ahora se establece un espacio intensificado de control sobre los sujetos.

A esta última conclusión debemos agregar la posibilidad de que, ante el incumplimiento de alguna de las medidas establecidas en la libertad vigilada o reclusión parcial y verificadas por medio del monitoreo telemático, se deje sin efecto la medida sustitutiva, imponiendo la pena de privación de libertad original (Art. 26 de la Ley $\mathrm{N}^{\circ}$ 20.603). De este modo, por medio de la monitorización podría aumentar el numero de privaciones de libertad, toda vez que existe un mecanismo de vigilancia intensificado del cumplimiento de las condiciones impuestas por el tribunal sobre los sujetos, en un espacio en el que antes no existía tal control. Así, uno de los grandes objetivos de la Ley $\mathrm{N}^{\circ}$ 20.603, disminuir el número de reclusos, podría verse traicionado. No obstante, es importante destacar que esta conclusión debe ser sostenida como una hipótesis teórica, ya que los resultados empíricos en materia de reincidencia y efectividad han sido contradictorios. ${ }^{60}$

De esta forma, siguiendo con lo planteado precedentemente, hacemos nuestras las conclusiones de Zaffaroni en relación con los objetivos de las medidas alternativas a la privación de libertad (en nuestro caso, medidas sustitutivas a la privación de libertad):

\footnotetext{
${ }^{59}$ Esto se manifiesta en la diferencia en la aplicación del monitoreo telemático entre la libertad vigilada y la libertad vigilada intensiva, si entendemos que la antigua libertad vigilada tiene un correlato, en su aplicación, con la actual libertad vigilada "simple". Adicionalmente, esto se aclaró en la discusión en particular al interior de la Comisión de Constitución, Legislación y Justicia ante una objeción del diputado Jorge Burgos: "Precisaron que en el caso de la pena sustitutiva de la libertad vigilada simple, no se contemplaba la aplicación de este sistema, por cuanto no interesaba mantener al condenado en un lugar determinado, sino más bien someterlo a una terapia de rehabilitación y a programas determinados. En cambio, en el caso de la libertad vigilada intensiva, sí existía especial preocupación por el control del penado y, por ello, se permitía la aplicación del sistema telemático". Historia de la Ley... (nota 44), p.113.

${ }^{60}$ Las investigaciones son las de Bonta, Wallace-Captretta y Rooney (2000) y de Padgett, Bales y Blomberg (2006) (efectividad de la vigilancia electrónica y los efectos que genera en la reincidencia). En Padgett, Kathy, Bales, William and Blomberg, Thomas: Under Surveillance: an empirical test of the effectiveness and consequences of electronic monitoring, 2006, pp. 62-89 y Bonta, James; Wallace-Captretta, Suzanne and Rooney, Jennifer: Risk-need-responsivity model for offender assessment and rehabilitation. 2000. En http:// www.publicsafety.gc.ca/res/cor/rep/risk_need_200706-eng.aspx
} 
Peña - Monitoreo telemático...

En realidad, establecer en el Código Penal sanciones no privativas de libertad, puede tener en la práctica distintos resultados. Uno de ellos es que se queden en el Código Penal y que los jueces no las apliquen nunca (...). Otro es que estén en el Código Penal y que se apliquen a personas que, de otra forma, nunca serían encarceladas, con lo cual aumentaría un poco el ámbito de lo punible (...). Están en el Código Penal y (...) tenemos el mismo número de presos, o bien (...) un número parecido o superior de condenados a penas no privativas de libertad, con lo cual habríamos aumentado el número de penados sin disminuir el número de encarcelados. ${ }^{61}$

Es la extensión del ámbito de lo punible y del espacio de control ejercido por el Estado (mediante la vigilancia), en un contexto de libertad del sujeto, lo que surge como consecuencia del establecimiento de esta medida.

\section{Significado y constataciones de la medida}

\section{a) Violencia simbólica, control y vigilancia}

\section{i) Pena y violencia simbólica}

En Vigilar y Castigar, Foucault identifica que, a partir del siglo XVII, comienza la desaparición del castigo como un espectáculo público de violencia en contra del cuerpo del condenado. ${ }^{62}$ En efecto, con anterioridad, las sanciones penales constituían un amplio ritual de atrocidades en el que el cuerpo del sujeto era totalmente destruido en un despliegue de violencia autorizada. ${ }^{63}$ Como consecuencia de esta evolución, surge un arte de castigar que se apoyaría, desde ahora, en una tecnología de la representación. De este modo, la sanción sería concebida como un juego de signos-obstáculos que someterían los movimientos de las fuerzas a una relación de poder. Dichos signos deberían constituir el arsenal de penas por medio de los cuales el hombre se representa el suplicio en todo momento. En consecuencia, la sanción penal sería un medio de comunicación simbólica mediante el cual se trasmitiría la posible sanción. ${ }^{64}$

\footnotetext{
${ }^{61}$ Zaffaroni, Eugenio Raúl: “¿Qué hacer con la pena? Las alternativas a la prisión”. En: Cuadernos para la Reforma de la Justicia, 2. Las penas sustitutivas de prisión. Disponible en http:/ / criminet.ugr.es/recpc/ recpc_03-05.btml Para un análisis de la relación entre medidas alternativas a la privación de libertad y el control social, véase Chinchilla, Rosaura y Linares, Érika: Penas Alternativas a la Prisión ¿Menos cárcel o más control social? (análisis del proyecto de Código Penal). Disponible en:http:/ / maestriaenderechopenal.com/documentos/textos/PENAS\%20ALTERNATIVAS\%20A\%20LA\%20 PRISION-menos\%20carcel.pdf

${ }^{62}$ Foucault, Michel: Vigilar y Castigar... (nota 52), p 69.

${ }^{63}$ Garland, David: Castigo y Sociedad Moderna. Un estudio de teoría social, 1999, p. 165.

${ }^{64}$ Ibid., pp. 96-104.
} 
Tal representación no solo produciría efectos para el potencial criminal, sino también constituye una lección para toda la población. Se transmitiría un conjunto de significados que obstaculizarían el crimen tanto al potencial infractor como a la sociedad en general.

Toda sanción penal, en este sentido, no solo tendría una dimensión física expresada en la coacción al cuerpo del sujeto, sino también una dimensión simbólica que, por medio del discurso, transmite un significado ${ }^{65}$ al condenado y a la sociedad. Esto se manifestaría tanto en el momento previo a la sanción, por medio de la representación del castigo, al momento de la ejecución, como ejemplo para la población, y con posterioridad a la aplicación, como normalización del sujeto. ${ }^{66}$

Esta constatación histórica nos permite entender la forma en que surge la sanción que supera al teatro del horror de la época clásica ${ }^{67}$ y que constituye el paradigma de sanción actual.

Aquella dimensión de la sanción permitiría describir el sentido de la institución desarrollada en este trabajo. En efecto, la monitorización es una sanción que obliga al individuo a portar un dispositivo que envía señales acerca de su ubicación espacial. De este modo es posible controlar el cumplimiento de las medidas que establece el juez tanto en la reclusión parcial como en la libertad vigilada intensiva. Sin embargo, la medida no solo sería aquello que se nos presenta físicamente. Constituiría además, como toda sanción, un mensaje simbólico que transmite un significado previo a su imposición, al momento de la misma y con posterioridad a su aplicación.

Dicho significado es que el sujeto se encuentra sometido a una vigilancia en todo momento. El individuo, en este sentido, portaría un dispositivo que transmitiría un mensaje de cuidado y control, que sometería al sujeto y a su cuerpo a una situación de vigilancia permanente.

Esta sanción también tendría un significado para la sociedad en general. El contenido de este mensaje muestra que tal sujeto ha sido sometido a una sanción de determinadas características. El porte de aquel dispositivo manifestaría a la sociedad las características del sujeto con quien tratan. ${ }^{68}$ Por tanto, al conocer el

\footnotetext{
${ }^{65}$ Sostiene Foucault que la sanción en esta época manifestaría una transparencia del signo a lo que significa, sosteniendo que no se opone ya lo atroz a lo atroz, sino una relación de representación del hecho delictivo a la sanción.

${ }^{66}$ En este punto aún puede obviarse el efecto directo sobre el cuerpo del sujeto. Será desarrollado, sin embargo, en el punto siguiente.

${ }^{67}$ Foucault utiliza este concepto para describir el periodo moderno, a saber, finales del siglo XVI, el siglo XVII y principios del siglo XVIII. Garland, David: Castigo y Sociedad Moderna... (nota 63), nota al pie número 9 .

${ }^{68}$ En este sentido, podría sostenerse que dichas medidas cumplirían, además, la función que antes realizaron las penas estigmatizantes: la diferenciación y la marginación.
} 
Peña - Monitoreo telemático...

carácter del individuo podrían ejercer una función adicional de control. De este modo, al sancionado se le enviaría un segundo mensaje, que manifestaría no solo el control institucional, por el órgano estatal correspondiente, sino también que la comunidad conoce su situación y observará sus movimientos. ${ }^{69}$

Sin embargo, la comunicación simbólica no solo tendría implicancias por la emisión de un discurso, sino también mediante el discurso sería posible alcanzar ulteriores efectos.

Es por medio de Bourdieu, quien analiza el "lenguaje como instrumento del poder y acción", ${ }^{70}$ que podemos llegar a una conclusión ulterior en el asunto. A partir de un análisis de las condiciones sociales de producción de enunciados, ${ }^{71}$ podría entenderse que dicha dimensión simbólica permite naturalizar una relación de dominación. Esto es llamado violencia simbólica, y la define de la siguiente forma:

La violencia simbólica es esa coerción que se instituye por mediación de una adhesión que el dominado no puede evitar otorgar al dominante (y, por tanto, a la dominación) cuando sólo dispone, para pensarlo y pensarse, o mejor aún, para pensar su relación con él, de instrumento de conocimiento que comparte con él y que, al no ser más que la forma incorporada de la estructura de la relación de dominación, hacen que ésta se presente como natural. $^{72}$

En efecto, sostiene el autor que la dominación, aun cuando se base en la fuerza más cruda de las armas o el dinero, tiene siempre una dimensión simbólica. Dicha dimensión establecería actos de sumisión que, como tales, recurren a estructuras cognitivas susceptibles de ser aplicadas a todas las cosas del mundo y, en particular, a las estructuras sociales. ${ }^{73}$ En términos explícitos, violencia simbólica sería el modo en que los dominados aceptan como legítima su propia condición. Esto supone,

\footnotetext{
${ }^{69}$ Una posible pregunta que podría surgir sería: ¿Qué ocurre cuando el sujeto logra ocultar el mecanismo (v. gr., bajo sus ropas)? La respuesta que podría darse a este punto es que no resulta importante el hecho de que el individuo pueda eludir las consecuencias del mecanismo. La pregunta relevante es la institucional, a saber, ¿resulta legítimo introducir una medida que genere la posibilidad de un debilitamiento de los vínculos comunitarios mediante la marginación de quien lo porta? Que la consecuencia efectivamente y en todos los casos se produzca no resulta decisivo, sino lo que importa realmente es la creación de instituciones, por parte del Estado, que generen la posibilidad de producir sujetos estigmatizados al interior de la sociedad. No resulta correcto evaluar a las instituciones por la posibilidad de eludir sus efectos.

70 Bourdieu, Pierre y Eagleton, Terry: Doxa y vida cotidiana: una entrevista. En Žižek, Slavoj, Ideología, Un mapa de la cuestión, 2003, p. 295.

${ }^{71}$ Ibid.

72 Bourdieu, Pierre: Meditaciones pascalianas, 1990, pp. 224-225.

${ }^{73}$ Ibid., p. 227.
} 
REJ - Revista de Estudios de la Justicia - No 18 - Año 2013

además, la capacidad de imponer la visión legítima del mundo social y de sus divisiones. $^{74}$

La aceptación de dicha dominación (de sexo, etnia, cultura, lengua, etcétera) no se ejerce en la lógica de las conciencias cognitivas, sino en la oscuridad del habitus. Este concepto abarca las disposiciones inculcadas en el agente por los aspectos insignificantes de la vida cotidiana, en el comportamiento corporal o en los múltiples modos de ver las cosas o hablar de ellas. ${ }^{75}$ En este sentido, el poder simbólico solo se ejerce con la colaboración de quienes lo padecen, porque contribuyen a establecerlo como tal.

En consecuencia, mediante la inscripción de tal poder en el cuerpo de los sujetos $-\mathrm{y}$ en sus esquemas de percepción y acción- es posible naturalizar y legitimar una relación de dominación que permita imponer la visión legítima del mundo social y de sus divisiones. Este efecto de la transmisión de significados es lo que el autor francés llama violencia simbólica.

Este fenómeno puede ser aplicado al monitoreo telemático hasta el punto en que lo habíamos dejado. En efecto, sostuvimos que el carácter simbólico de la sanción permite transmitir el significado de la misma al momento de ejecutarla. El significado de la medida supone imponer al sujeto la sensación del control no solo desde el Estado, sino también desde el resto de los sujetos, de sus disposiciones corporales. Así, mediante los efectos simbólicos de la sanción, que transmiten un mensaje de la vigilancia permanente por medio del dispositivo al sujeto y a la sociedad, podría naturalizarse y legitimarse una relación de dominación que se basa en un vínculo de control permanente. Esta relación de dominación se aplicaría por medio de la colaboración del individuo (en términos de su habitus). De este modo, es posible imponer una visión legítima del mundo social por parte de los grupos dominantes ${ }^{76}$, sin previa oposición de los subordinados.

Además, dicho mensaje de vigilancia y control permanente no solo se impondría directamente por parte del Estado (o de los grupos de poder que lo controlan), sino también indirectamente por medio de la sociedad que colabora con dicha vigilancia. Así se legitimaría una relación en la que el Estado y la sociedad actúan como un mecanismo de control totalizante.

\footnotetext{
${ }^{74}$ Fernández, J. Manuel: "La noción de violencia simbólica en la obra de Pierre Bourdieu: una aproximación crítica”, 2005, p. 12.

75 Ibid., p. 19.

${ }^{76}$ En su obra La reproducción, Bourdieu sostiene por violencia simbólica la forma de imponer significaciones arbitrarias como legítimas, disimulando las relaciones de fuerza entre los grupos o clases que constituyen la formación social. Será el grupo dominante quien impondrá, por medio de la acción pedagógica, su arbitrariedad cultural. Bourdieu, Pierre: La reproducción, 1996, pp. 43-49.
} 
Peña - Monitoreo telemático...

\section{ii) Disciplina y control del cuerpo}

Durante el curso de la época clásica, sostenía Foucault, el cuerpo es descubierto como objeto y blanco de poder. Se idearon dos registros en torno a este concepto: sumisión y utilización, cuerpo útil, cuerpo inteligible. ${ }^{77}$ De esta forma, nace toda una política y teoría en torno a la noción de cuerpo. Se lo concibe, ahora, a base de la noción de "docilidad" que une al cuerpo analizable con el cuerpo manipulable. Estas manifestaciones de control de los sujetos son llamadas disciplinas.

Con el nacimiento de las disciplinas, nace una política de coerciones calculadas, con el objeto de normalizar al individuo, es decir, hacerlo más útil y obediente. Foucault llama a dicha política "microfísica del poder". Esa forma estratégica de coerción se manifiesta desde el momento en que las relaciones de fuerzas penetran el cuerpo del sujeto con el fin de influir en lo que él llama "alma" (i.e. núcleo de dirección de la conducta). ${ }^{78}$ De este modo, se produciría un individuo que hace lo que se le pide sin necesidad de aplicar una fuerza exterior sobre él.

El derecho es uno de los mecanismos por los cuales se lleva a cabo dicha función de normalización y disciplina. Si bien no es exclusiva de ella ${ }^{79}$ la ley es una de las formas de conseguir la sumisión del cuerpo de los individuos. De este modo, el Estado (liberal), en tanto cuerpo creador de leyes, puede llevar a cabo esta función de normalización.

El fundamento alrededor de esta acción del Estado como intervención en la vida de los individuos surge unido al concepto de gobierno y al razonamiento que trae consigo. En efecto, luego del nacimiento del capitalismo y con el cambio de fundamento del poder soberano, el gobierno es entendido como un "poder que se ejerce positivamente sobre la vida, que procura administrarla, aumentarla, multiplicarla, ejercer sobre ella controles precisos y regulaciones generales" ${ }^{80} \mathrm{De}$ este modo, el gobierno del territorio se convierte en la gestión de la población, los individuos con sus ritmos de natalidad, mortalidad, enfermedad, moralidad, etc. ${ }^{81}$ El estudio de la intervención del Estado en estas materias es lo que se llama biopolitica.

Dicha forma de actuación se deriva fundamentalmente de la forma de razonamiento del gobierno liberal. Esta racionalización gubernamental da cabida a la actuación mecánica-natural de los comportamientos y de la producción. Pero tal

\footnotetext{
${ }^{77}$ Foucault, Michel: Vigilar y Castigar... (nota 52), p. 125.

${ }^{78}$ Garland, David: Castigo y Sociedad Moderna... (nota 63), p. 167. Foucault, Michel: La microfísica del poder, p. 4.

${ }^{79}$ Foucault, Michel: Un diálogo sobre el poder y otras conversaciones, 2001, p. 97: [El poder] "no obedece a la forma única de lo prohibido y del castigo, sino que tiene formas múltiples".

${ }^{80}$ Foucault, Michel: Historia de la sexualidad. Volumen I. La voluntad del saber, 1998, p. 82.

${ }^{81}$ Ugarte, Javier: Biopolitica. Un análisis de la cuestión, 2006, p. 2.
} 
como da cabida a ello sin intervenir directamente, se circunscribe a la función de vigilancia y control de los sujetos cuando ve que algo no acaece como lo quiere la mecánica general de los comportamientos económicos. ${ }^{82}$ De esta forma, se busca la disciplina y normalización de los sujetos con el fin de obtener de estos los comportamientos que exige el trabajo en las fábricas, el ejército y la colonización. ${ }^{83}$

Esto describe el nacimiento de un Estado que, en tanto actuación como gobierno, utiliza control, normalización y disciplina para lograr una docilidad del cuerpo y comportamiento de los sujetos mediante sus distintas instituciones. Considero que el monitoreo telemático constituye uno de estos mecanismos. Sin embargo, a diferencia del resto de las instituciones, la monitorización permitiría alcanzar un grado de control y docilidad del cuerpo nunca antes vista.

Dicho control se produce por las señales que envía el dispositivo a los centros de monitorización. Estos centros reciben la información enviada por el dispositivo y comunican la trasgresión de alguna medida impuesta por medio de la libertad vigilada intensiva (ubicación espacial o realización de ciertas actividades), o el incumplimiento de las restricciones de movimiento propias de la reclusión parcial.

De esta forma sería posible una inmediata reacción del Estado frente a infracciones o alteraciones del mecanismo. En efecto, si bien es necesario destacar que el reglamento establece en su artículo 19 una diferencia entre avisos, prealarmas y alarmas (que contemplan distintas reacciones, dependiendo de la infracción o alteración del dispositivo), el Estado sí podría llevar un análisis acabado y constantemente actualizado de toda novedad que contemple el aparato. Así, podrían tomarse las determinaciones necesarias al momento de presentarse alguno de los eventos puntualizados: aviso a las policías de la infracción de algunas de las medidas, proximidad a alguna zona de exclusión, incumplimiento de la reclusión parcial, etcétera.

En consecuencia, surge un control total del comportamiento del sujeto. En primer lugar, porque sus movimientos se encontrarían registrados, pero además, porque toda infracción podría encontrar una pronta reacción estatal.

En segundo lugar, y unido al apartado pena y violencia simbólica, de este capítulo, la coerción que permite aquel control total en las disposiciones corporales del sujeto proviene del propio individuo. En efecto, mediante la imposición de un mensaje simbólico, que imprime una concepción de vigilancia permanente sobre si mismo, se genera una situación en la que él se abstendría de actuar ante la preocupación de un registro y reacción del Estado y la sociedad.

\footnotetext{
${ }^{82}$ Foucault, Michel: El nacimiento de la biopolítica, 2007, p. 89.

${ }^{83}$ Ugarte, Javier: Biopolítica... (nota 81), p. 2.
} 
Así, se produce una totalización del control: primero, por una reacción punitiva estatal inmediata y, segundo, por medio de la imposición de aquella concepción en las disposiciones corporales del propio sujeto.

Por tanto, la monitorización permite, por conducto de la vigilancia permanente, un control total de los movimientos y de la ubicación espacial. Con una coerción débil, pero mecánica y constante, de un dispositivo que se inserta en el cuerpo y que informa cada uno de sus movimientos, se alcanzaría un grado de control que permite una modulación total de su comportamiento. Por medio de esta intervención permanente del Estado se alcanza una normalización del individuo, regulando completamente su actuar. Se establece una relación de dominación total, imponiendo formas de actuación, volviendo útil y obediente al portador del mecanismo, generando, en definitiva, sujetos que hacen lo que se les pide sin necesidad de imponer una fuerza exterior sobre ellos.

\section{iii) Vigilancia}

La manifestación arquitectónica de la composición vigilancia, control y normalización es el Panóptico de Jeremy Bentham. La obra del filósofo inglés consistía en la descripción de una cárcel en forma de anillo junto a una torre en el centro. Este dispositivo central contaba con anchas ventanas desde las cuales se podía observar todo lo que ocurriría al interior del anillo. ${ }^{84}$

Dicha obra constituía, según sostiene Foucault, el perfeccionamiento de la vigilancia. En efecto, posee dos elementos fundamentales: en primer lugar, permite una visibilidad constante sobre un punto. El sujeto es visto permanentemente y sabe que así ocurre. En segundo lugar, a aquella visibilidad constante se le suma la imposibilidad de ser visto. Así, quien vigila al interior de la torre no resulta reconocible por quien resulta observado. Este dispositivo carcelario permite disociar la pareja ver-ser visto. ${ }^{85}$

Según dicha disociación se produciría el efecto mayor del Panóptico, a saber, inducir en el detenido un estado consciente y permanente de visibilidad que garantiza el funcionamiento automático del poder. ${ }^{86}$ De esta forma no habría que accionar el mecanismo de la vigilancia, aquel siempre estaría ahí volviendo inútil la actualidad de su ejercicio. De hecho, resultaría irrelevante que existiera un sujeto al interior de la torre. Es aquel efecto, por medio del cual el sujeto se siente permanentemente vigilado al observar el dispositivo central, el que induce al individuo al comportamiento esperado.

Esta vigilancia produciría sus efectos en los sujetos al encontrarse estos insertos en una relación de poder que ellos mismos portan. Tal como lo sostiene

\footnotetext{
${ }^{84}$ Foucault, Michel: Vigilary Castigar... (nota 52), p. 184.

${ }^{85}$ Ibid., p. 186.

${ }^{86}$ Ibíd, p. 185.
} 
REJ - Revista de Estudios de la Justicia - No 18 - Año 2013

Foucault, quien se encuentra sometido a esta visibilidad, y que lo sabe, reproduce e inscribe en sí mismo la relación de poder, convirtiéndose en el principio de su propio sometimiento. ${ }^{87}$

Por medio de este mecanismo que analiza la distribución de los cuerpos, sus combinaciones y desviaciones, podría individualizarse perfectamente al sujeto obstáculo, logrando una corrección eficaz y económica.

Este esquema de vigilancia, pese a ser un dispositivo carcelario, se encontraría destinado a difundirse en el cuerpo social. De esta forma, las fuerzas sociales -moralidad pública, producción económica, instrucción, etc.- y sus instituciones fundamentales -familia, hospital, escuela, fábrica, etc.- podrían volverse más sólidas al vigilar el desempeño de los sujetos. En definitiva, este procedimiento de subordinación de los cuerpos lograría volver más difusas las disciplinas por medio de su inserción en cuerpo social entero. Así, el ejercicio del poder sería más eficaz, más rápido, más ligero, instaurando, de esta forma, toda una sociedad disciplinaria. ${ }^{88}$

De acuerdo con lo que sostiene Foucault, el sueño de la burguesía era la vigilancia total ejercida por un solo individuo. Dicho sueño fue realizado, sostiene el autor, por una forma de gobierno en que ningún individuo pudo quedar fuera de la vigilancia del Estado, ninguna zona oscura existía, todo el mundo se encontraba vigilado. La figura que representa esta escena es el Estado napoleónico. ${ }^{89}$ Durante el siglo XX, en la descripción del autor francés, se difumina el ejercicio directo del poder, trasladando la vigilancia a todas las instituciones fundamentales de la sociedad, a saber, familia, fábrica, manicomio, escuela, etc. De esta forma, en la obra de este autor se postulaba que la cárcel desaparecería, toda vez que se produciría una multiplicación de los sistemas disciplinarios en dichas instituciones, pasando a quedarse con la mayor parte de los sistemas de sanción y control, perdiendo la prisión el motivo por el cual existir.

Esta fue la concepción dominante hasta la primera mitad del siglo XX. Sin embargo, a mediados de ese siglo, con el surgimiento de otras tecnologías, cambia la forma de ejercer la vigilancia al interior del cuerpo social. La sociedad disciplinaria desaparece, dando paso a lo que Gilles Deleuze llamó "sociedades de control". Veremos que la idea de una vigilancia total de un espacio continúa (Panóptico), ahora, sin embargo, en el contexto de un cambio de modelo de sociedad.

\footnotetext{
${ }^{87}$ Ibid., p. 187.

${ }^{88}$ Ibid., pp. 191-193.

${ }^{89}$ Foucault, Michel: Un diálogo sobre el poder... (nota 79), pp. 78-79.
} 
Peña - Monitoreo telemático...

\section{iv) Sociedades de control}

La sociedad descrita en el apartado anterior corresponde a la llamada "sociedad disciplinaria". Deleuze sostiene que dichas sociedades, expuestas magníficamente por Foucault -y que tendrían su apogeo a finales del siglo XIX y principios del siglo XX-, fueron reemplazadas por las llamadas "sociedades de control". La diferencia, y el paso que marca la evolución de una a otra, es la siguiente: las primeras operaban mediante la organización de grandes aparatos de encierro. ${ }^{90}$ Esto explica la idea de que el control, la disciplina y la vigilancia se ejercían en lugares o "anillos" entre los cuales el sujeto se desplazaba. Así, el movimiento iba de la fábrica al hospital, a la familia, a la cárcel, etc., cada una con sus leyes, cada una con su lenguaje, a los cuales el individuo se sometía. Ahora, las "sociedades de control" buscan plasmar su lenguaje de coerción, sanción y vigilancia al aire libre, es decir, se produce un funcionamiento continuo de la observación. Podría decirse que ahora el control se desplaza y acompaña al sujeto.

Foucault habría reconocido, según Deleuze, que las sociedades descritas por él se encontraban cercanas a su desaparición. Ahora serían aspectos como la deuda económica, la información online y el marketing (como dispositivo constante de clasificación y control) los que dominan las disposiciones del sujeto. Las fronteras creadas por las instituciones de antaño, ahora serían difusas. Todo sería un continuo: en un régimen de control nada se termina nunca. ${ }^{91}$

El autor analizado menciona explícitamente el "collar electrónico" como la manifestación punitiva de la sociedad de control. Así sería posible la vigilancia continua sobre el sujeto, sería posible "proporcionar a cada instante la posición [del] elemento en un medio abierto". ${ }^{92}$ El nacimiento del monitoreo telemático podría constituir el resurgimiento del anhelo burgués de vigilarlo todo. En efecto, este dispositivo, por medio de la emisión de señales, podría registrar los movimientos del sujeto y su ubicación espacial, permitiendo que un centro de información conozca las disposiciones corporales de todos los individuos bajo la medida.

Podría decirse que la vigilancia constante sobre el sujeto, sin poder ver quién se encuentra vigilándolo, reproduce la idea de la torre central foucoultiana. Sin embargo, el agregado de esta medida es que la concepción de la vigilancia total, propia de la cárcel (mediante la ingeniería del Panóptico), se trasladaría a la ciudad. En este sentido, el espacio donde los sujetos pueden ejercer su libertad, en tanto ciudadanos, se transforma en un espacio en donde el Estado podría extender sus redes de control y sanción. De esta forma, el surgimiento de una ciudad-cárcel es inminente.

\footnotetext{
${ }^{90}$ Deleuze, Gilles: Conversaciones 1972-1990, p. 150.

${ }^{91}$ Ibid., p. 148.

92 Ibid., p. 154.
} 
A esto se agregaría una segunda dimensión. El porte del dispositivo permitiría que todo ciudadano pudiera observar quiénes son los individuos sujetos a la medida. De este modo, las redes de observación y vigilancia no solo surgirían desde el Estado, sino que se extenderían a todo el cuerpo social, permitiendo que todo sujeto vigile a quien se encuentre bajo la medida. La ciudad-cárcel es inminente, entonces, no solo porque los detenidos serían vigilados por el Estado en todo momento, sino también porque los ciudadanos podrían apoyar dicha medida de control con una vigilancia ejercida por ellos mismos.

Si a lo anterior agregamos lo desarrollado en los apartados precedentes, los ideales de control, vigilancia y normalización resurgirían -junto a un nuevo modelo social- con más fuerza que nunca. La generación de un dispositivo de vigilancia total en el cuerpo del individuo, que ejerce un control en sus disposiciones físicas y psicológicas, permitiría el nacimiento de sujetos disciplinados y obedientes, por sobre los espacios de libertad exigidos en una sociedad democrática. ${ }^{93}$ Pero a ello se agrega una segunda conclusión: se inserta dicho mecanismo al interior de la ciudad, permitiendo que todo el mundo ejerza el control sobre la población sujeta a la medida. Surgiría así un régimen de desconfianza universal que impediría el recíproco reconocimiento entre ciudadanos pertenecientes a una misma comunidad política, destruyendo todo vínculo social y comunitario al interior de la ciudad. $^{94}$

\section{b) Monitoreo telemático, Estado penal y privatización de la justicia}

La segunda parte de este análisis sociológico del monitoreo telemático resulta ineludible. Es necesario caracterizar la medida en el contexto general de la desaparición del Estado de Bienestar, en conjunto con la decadencia del fordismo, y en el surgimiento de un Estado penal, como fruto del nacimiento y consolidación de neoliberalismo económico. De esta forma sería posible describir la monitorización como una manifestación de los cambios producidos, a fines del siglo XX, vinculados a la praxis penal y mecanismos de control por parte del

\footnotetext{
${ }^{93}$ El trabajo de Iglesias y Pérez (2006) comparte nuestras conclusiones. Sin embargo termina por aceptar la utilización de la medida sin hacerse cargo de dichas críticas, solo en la medida que satisfaga el contenido del principio de necesidad (especialmente, del criterio de menos lesividad posible no entendiendo el mecanismo como contrario a la Constitución), los fines preventivos de la pena, se acompañe de programas de resocialización y como complemento a algunas sanciones al interior del sistema (sanción por multa impaga y control de libertad anticipada. Como pena principal, solo aquellas que impliquen privación de libertad por pequeños lapsos). En Iglesias, Miguel Ángel y Pérez, Juan Antonio: La pena de localización permanente... (nota 8), pp. 1071-1107.

${ }^{94}$ De Giorgi, Alessandro: El gobierno de la excedencia. Postfordismo y control de la multitud, 2006, p. 133. Žižek sostiene en Sobre la violencia que en la era de la "pospolítica" el único modo de introducir la pasión y movilizar a la gente en este campo es por el miedo. Es el miedo a lo otro el principio movilizador fundamental. En Žižek, Slavoj: Sobre la violencia. Seis reflexiones marginales, 2009, pp. 5592. Esto puede ligarse con lo dicho anteriormente respecto de la vigilancia radicada en la sociedad y la exclusión del monitorizado, destruyendo las bases de la comunidad política.
} 
Peña - Monitoreo telemático...

Estado y, más aún, al interior de un sistema que sufre un cambio de su estructura social y económica.

En este sentido es que Garland intenta llevar a cabo una "historia del presente" acerca de las instituciones penitenciarias. En efecto, por medio de una genealogía del castigo penal y del delito en la sociedad tardío-moderna, busca explicar las fuerzas que dieron origen a las prácticas penales de esta época y a identificar las condiciones sociales e históricas mediante las cuales se desarrollaron.

De esta forma intenta caracterizar la era del post-wellfarismo penal por medio de la evolución que han vivido las instituciones que envuelven el control del delito y el castigo estatal. No obstante, sostiene la existencia de una etapa de postrehabilitación en la que vivimos. Plantea que estas estructuras no viven cambios puros, sino más bien son estructuras que expresan el cambio y la continuidad.

Entre los elementos más relevantes para describir los aparatos penales, sostiene el surgimiento de instituciones privadas encargadas de la prevención y seguridad. De este modo surge una asociación entre el ámbito público y privado, por esquemas de policía comunitaria y prácticas multiagenciales que generan una intervención de la sociedad civil en el tratamiento delictivo. Dicho tratamiento tendría por objeto la prevención del delito (detectar factores de riesgo), reducción del daño y del miedo, y el control del gasto. ${ }^{95}$

Por otro lado, sostiene el surgimiento de una nueva cultura de control de delito. Esto ha generado compromisos normativos, nuevas sensibilidades emocionales y nuevos propósitos institucionales. A partir de lo anterior, surgen dos consecuencias fundamentales: la primera de ellas dice relación con un welfarismo penal modificado. Esto se caracteriza por la consolidación de la responsabilidad individual y de la seguridad pública, con los efectos retributivos, incapacitantes y disuasivos de la sanción. La segunda de ellas se basa en el nacimiento de un razonamiento de la justicia penal de carácter económico. En efecto, con anterioridad a este tipo de razonamiento, los problemas del delito se caracterizaban por presentar una causa social y una solución social. Los problemas particulares que surgían en torno al crimen debían rastrearse siempre en su raíz social. Sin embargo, en la actualidad, ha surgido un tipo de razonamiento que establece un énfasis en la responsabilidad individual y un lenguaje económico del "costo-beneficio", "mayor provecho por dinero empleado" y "responsabilidad fiscal", es decir, una concepción del daño social, costos y beneficios sociales a partir de la sanción. ${ }^{96}$

\footnotetext{
95 Garland, David: La cultura del control. Crimen y orden social en la sociedad contemporánea, 2005, pp. 279281.

${ }^{96}$ Ibid., 313-331.
} 
De este modo, Garland nos ofrece una descripción del delito y del castigo penal al interior de la sociedad tardío-moderna que ofrece elementos que caracterizan muchos aspectos propios de la justicia penal actual y de la monitorización.

En especial, resultan fundamentales los argumentos expuestos en torno al resurgimiento de una racionalidad económica detrás del análisis del control y castigo penal. En efecto, dicho razonamiento (como será explicado Infra) resulta importante al momento de describir el nacimiento del monitoreo telemático. De este modo, el surgimiento de medidas que tiendan a disminuir los costos de la prisión, del control y de la sanción, comienzan a ser los elementos más relevantes al momento de adoptar decisiones y adoptar políticas públicas.

Por otro lado, la descripción de un énfasis en la seguridad y prevención del delito resultan decisivas para la investigación que nos convoca. En efecto, en la monitorización se expresa un razonamiento que busca la anticipación en la comisión de los crímenes, una reacción punitiva eficaz y el control del sujeto, como medio de imposibilitar la infracción de medidas alternativas a la privación de libertad. De esta forma, al igual que Garland, se ha sostenido que estas medidas constituyen una extensión del ámbito del control formal del delito, que se inserta en la sociedad y busca prevenir todo hecho riesgoso.

Wacquant, en Castigar a los pobres, sostiene un análisis en el que describe la evolución institucional que dio origen al cambio en la práctica punitiva estatal en Estados Unidos a fines del siglo XX. En efecto, describe el autor que a partir del último tercio de dicho siglo (desde la reelección de Richard Nixon, en 1972) comienza una paulatina disminución en la protección social entregada por el Estado. Conjuntamente se produce un aumento en la inyección de recursos en los aparatos de persecución penal. De este modo, la lucha contra el crimen comienza a servir de coartada para contrarrestar la demanda de una expansión del Estado Social, ${ }^{97}$ produciéndose un giro en las prioridades del Estado, desde lo social hasta lo penal.

El autor caracteriza a este proceso de crecimiento del "brazo penal del Estado" como el paso del Wellfare (Estado de Bienestar) al Workfare y Prisonfare. Estos últimos conceptos servirían para describir el paso a un Estado neoliberal que disminuye al mínimo la ayuda social, incentivando el trabajo asalariado precarizado y planteando una guerra en contra de la delincuencia de las clases pobres del país. ${ }^{98}$

Esto generaría una expansión nunca antes vista del Estado penal y una criminalización de las consecuencias de la pobreza creada por el Estado.

\footnotetext{
${ }^{97}$ Wacquant, Loïc: Castigar a los pobres... (nota 53), p. 227.

${ }^{98}$ Ibid., pp. 88-100.
} 
El cambio en la praxis penal viene dado en el tratamiento de dichas poblaciones. En primer lugar destaca el aumento del recurso de la prisión, lo que traería aparejada una hiperinflación carcelaria nunca antes vista. En segundo lugar, dicha expansión del recurso carcelario se daría fundamentalmente en los delitos callejeros y faltas menores (delitos de desórdenes y drogas), generando extensiones de control y vigilancia en aquellos delitos cometidos, mayoritariamente, por las clases populares. Finalmente, el endurecimiento de las penas marcaría el tercer mecanismo que utilizó el Estado norteamericano para llevar a cabo su "lucha contra el crimen"."

Pero no solo aumentó el recurso de la prisión a partir de esta época. Se produce, además, una gran expansión en los mecanismos de vigilancia y control de las poblaciones ligadas a las fracciones más desfavorecidas de la clase trabajadora. ${ }^{100}$ Es así como nace una función de observación de las poblaciones díscolas y peligrosas mediante la formación de bases de datos con la información de los sujetos sometidos a penas privativas de libertad ${ }^{101}$ y la creación de sistemas de vigilancia electrónica de los delincuentes.

De este modo se manifiesta el surgimiento del Estado penal en Estados Unidos. El aumento del recurso carcelario y la intensificación de los mecanismos de vigilancia y control -con énfasis especial en el surgimiento del monitoreo telemático- son manifestaciones propias de un Estado en que trata la penalización como mecanismo generalizado de gestión en las poblaciones problemáticas. ${ }^{102}$ Este gobierno penal de la pobreza tiene por objeto final contener dichas manifestaciones delictivas, a fin de aumentar la sensación de seguridad del público y de las víctimas.

Por medio de esta lógica panóptica, sostiene el autor, se proscribe a los delincuentes de las ciudades, consolida su asilamiento social y aumenta su vulnerabilidad judicial, haciéndolos blancos de la exclusión social. ${ }^{103}$

Finalmente, De Giorgi sostiene que la lógica post-fordista de sanción se destaca por la aplicación de una concepción en la que el riesgo adquiere una relevancia fundamental. De este modo, las nuevas estrategias de persecución penal se caracterizan por ser dispositivos de gestión de riesgos y de represión preventiva de poblaciones que poseen determinadas características. Esta lógica, llamada por el autor actuarial, se basa en la identificación de clases de sujetos considerados como productores de riesgos y peligros. De este modo, son los indicios de probabilidad de comisión de algún hecho delictivo los que permiten clasificar a determinados sujetos como pertenecientes a clases peligrosas específicas. ${ }^{104}$

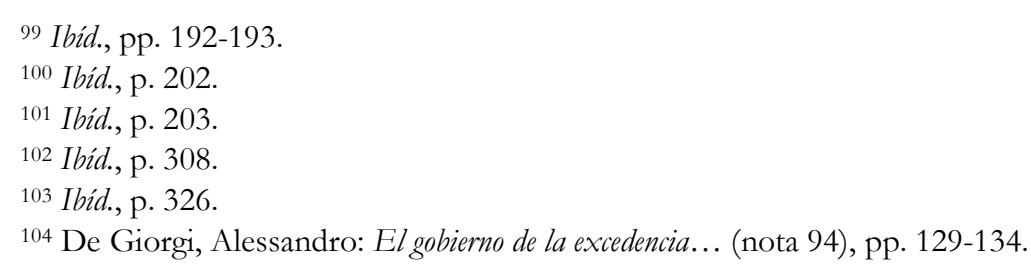


El actuarialismo persigue, por la aplicación de la lógica de los seguros individuales junto a las técnicas de control tradicionales, un control del delito que prescinde de la complejidad de lo real. De este modo, mediante el análisis costo beneficio propio de una racionalidad gerencialista, persiguen limitar, neutralizar y desestructurar formas de interacción social. Esto, ya que son percibidas como factores de riesgos. ${ }^{105}$

De esta forma, por medio de la actuación de los conceptos de análisis económico y de la racionalidad propia de los seguros, se persigue efectuar un control que tiene por objeto neutralizar al sujeto, destruyendo, de este modo, los vínculos sociales existentes con el mismo. ${ }^{106}$

El autor cita expresamente a la vigilancia electrónica como una manifestación de la lógica actuarial. En efecto, sostiene que por medio de la monitorización permitirían ser identificados los riesgos propios de una clase de delincuentes. Esto generaría el surgimiento de una ciudad punitiva, transformándose esta en un dispositivo de vigilancia y represión que se despliega sobre clases enteras de sujetos. De esta forma, "alimentan una geografía social completamente independiente de los comportamientos individuales, enderezada a la segregación y a la contención de clases de individuos definidos por su status". ${ }^{107}$ Así, los procesos sociales de construcción de diversidad social quedan completamente eliminados, toda vez que aparece una desconfianza universal en el otro. Esta fobia a lo extraño invade las prácticas sociales y penales, socavando los fundamentos del reconocimiento entre los sujetos.

\section{Conclusiones}

A lo largo de este trabajo se describió el modo de aplicación del monitoreo electrónico en el derecho comparado y su introducción en el derecho chileno. Así, pudo observarse que mayoritariamente se concibe como un mecanismo de apoyo a las medidas sustitutivas a la privación de libertad.

Es por el surgimiento de debate institucional y académico acerca de la crisis de la prisión y de la resocialización que las medidas alternativas y, posteriormente, las medidas sustitutivas a la privación de libertad llegan a Chile. Las consecuencias que ha traído el hacinamiento carcelario (riñas, incendios, intentos de fuga, etc.) y la ausencia de reinserción, han manifestado la necesidad de un mecanismo que permita evitar el delito de una forma distinta. Se intenta

\footnotetext{
105 Ibid., pp. 131-133.

106 De Giorgi, Alessandro: Tolerancia cero. Estrategias y prácticas de la sociedad de control, 2005, p. 55.

También en De Giorgi, Alessandro: El gobierno de la excedencia... (nota 94), p. 133.

107 Ibid., p. 135.
} 
Peña - Monitoreo telemático...

ahora, por medio de la entrega de un espacio de libertad al sujeto, poner fin a las consecuencias de la cárcel.

No obstante, dicho espacio de libertad podía ser limitado por el Estado, desde el momento que puede insertar, en las medidas de reclusión parcial y libertad vigilada intensiva, un dispositivo que permite controlar los movimientos del sujeto y determinar su ubicación espacial. En consecuencia, el objetivo del Estado era llegar a espacios donde antes no accedía, era ejercer un control en un contexto de libertad ciudadana.

Luego se sostuvo por medio de los conceptos violencia simbólica, control y vigilancia, que el monitoreo telemático constituye una medida que persigue el control de las disposiciones corporales del sujeto mediante una coerción débil pero constante. Dicha coacción se produce desde la vigilancia permanente del Estado, el que puede reaccionar inmediatamente a cualquier infracción de las medidas protegidas por el dispositivo. Pero, adicionalmente, se produce por la propia vigilancia efectuada por los ciudadanos quienes observan que el sujeto porta la medida. Finalmente, aquel control viene efectuado por el propio sujeto, toda vez que se representa por medio de la imposición de un mensaje simbólico basado en la vigilancia total del Estado y de la sociedad como observado en todo momento, cuestión que limita y condiciona cualquiera de sus movimientos. Este dispositivo de vigilancia permanente reproduciría el ideal carcelario del panóptico. Sin embargo, se agrega la posibilidad de ejercer aquel control en ausencia de coacción directa en encierro, ahora en la ciudad, ámbito espacial donde el sujeto despliega su libertad.

Este dispositivo de vigilancia, en definitiva, generaría un doble efecto. En primer lugar, centralizaría el control y la vigilancia del sujeto, generando efectos normalizadores, desde las propias disposiciones del Estado. Y en segundo lugar, permitiría, colateralmente, descentralizar dicho control en todos, pudiendo estos observar, vigilar y controlar la disposición espacial del condenado.

Por último, se intentó entregar una explicación contextual de la aparición del mecanismo. Por medio de Garland, Wacquant y De Giorgi se pudo apreciar que la existencia de la vigilancia electrónica obedece a una fase en las prácticas punitivas en las que la prevención del delito y la seguridad constituyen el objetivo de las instituciones sancionadoras. Esto se produce en un contexto en la que el Estado penal aparece como la expresión paradigmática de la organización social. Tal Estado dirige su acción al tratamiento carcelario de la pobreza, pero además a la vigilancia y el control de los individuos desviados. Se sostuvo que dicha forma de actuación obedecía una lógica actuarial, la que por medio del análisis de riesgos y probabilidades de comisión de delitos clasifica, trata y sanciona a los sujetos. De este modo se produce el surgimiento de una clase de individuos exentos de un reconocimiento igualitario, generando el fin del reconocimiento ciudadano y de los vínculos comunitarios. 
En consecuencia, con la monitorización se instala el discurso de un otro extraño en la sociedad, generándose exclusión y debilitamiento de los vínculos sociales. sostiene:

Para finalizar, se vuelve transparente la afirmación de Foucault cuando

La historia de la locura sería la historia de lo Otro - de lo que, para una cultura, es a la vez interior y extraño- y debe, por ello, excluirse (para conjurar un peligro interior), pero encerrándolo (para reducir la alteridad). ${ }^{108}$

Sin embargo, no es posible compartir la última parte de la cita. A lo largo de este trabajo se demostró que las técnicas de exclusión se han refinado hasta un punto tal que no resulta necesario el encierro para la separación de lo otro. Ahora, dicho acto se ejerce en la ciudad, espacio donde se producen las interacciones sociales libres y con el aporte de quienes participan de ellas.

${ }^{108}$ Foucault, Michel: Las palabras y las cosas, 1968, p. 9. En relación con esto, para un análisis de la pena aflictiva y de la pérdida de ciudadanía correlativa como una contradicción con el reproche de culpabilidad de la sanción, véase Mañalich, Juan Pablo: Pena y ciudadanía, 2006, pp. 63-83. 


\section{BIBLIOGRAFÍA}

* ARDLEY, Jenny: "The Theory, Development and Application of Electronic Monitoring in Britain", Internet Journal of Criminology, 2005.

* BARATTA, Alessandro: Criminología crítica y crítica del derecho penal, Siglo XXI Editores, Buenos Aires, 1986.

* BLACK, Matt and SMITH, Russell G.: "Electronic Monitoring in the Criminal Justice System”. Australian Institute of Criminology 245, 2003.

* BONTA, James; WALLACE-CAPTRETTA, Suzanne y ROONEY, Jennifer: Risk-needresponsivity model for offender assessment and rehabilitation, 2000. En: http:// www.publicsafety.gc.ca/res/cor/rep/risk_need_200706-eng.aspx

* BOTTOS, Shauna: An Overview of Electronic Monitoring in Corrections: The Issues and Implications. Correctional Service Canada, 2007.

* BOURDIEU, Pierre: La reproducción, Editorial Laia S.A., México D.F., 1996. Meditaciones pascalianas, Anagrama, Barcelona, 1999.

* BOURDIEU, Pierre y EAGLETON, Terry: "Doxa y vida cotidiana: una entrevista", en ŽIŽEK, Slavoj, Ideología, Un mapa de la cuestión, Fondo de Cultura Económica S.A., Buenos Aires, 2003.

* CESANO, José Daniel: "De la crítica a la cárcel a la crítica a las alternativas". Boletín mexicano de derecho comparado. Nueva serie, año XXXVI, número 108, 2003.

* CHINCHILlA, Rosaura y LINARES, Érika: "Penas alternativas a la prisión ¿Menos cárcel o más control social? (análisis del proyecto de Código Penal)". Revista de Ciencias Penales de Costa Rica. Disponible en, bttp:/ / maestriaenderechopenal.com/ documentos/textos/PENAS\%20ALTERNATIVAS\%20A $\% 20 L A \% 20 P R I S I O N-m e n o s \% 20$ carcel.pdf

* DELEUZE, Gilles: Conversaciones 1972-1990. Escuela de Filosofía Universidad ARCIS, Santiago.

* DE GIORGI, Alessandro: El gobierno de la excedencia. Postfordismo y control de la multitud, Traficantes de sueños, Madrid, 2006.

Tolerancia cero. Estrategias y prácticas de la sociedad de control, Lallevir, S.L./VIRUS Editorial, Barcelona, 2005.

* DI TELLA, Rafael and SCHARDGRODSKY, Ernesto: Criminal Recidivism after Prison and Electronic Monitoring. 2012. Disponible en: bttp:// wmw.econ.upf.edu/docs/seminars/ditella.pdf

* FERnÁndeZ, J. Manuel: "La noción de violencia simbólica en la obra de Pierre Bourdieu: Una aproximación crítica", Cuadernos de trabajo social, vol. 18, Universidad Complutense de Madrid, 2005.

* FOUCAULT, Michel: Vigilar y Castigar: el Nacimiento de la prisión, Siglo XXI Editores, Madrid, 2000.

El nacimiento de la biopolítica, Fondo de Cultura Económica, Buenos Aires, 2007. Historia de la sexualidad. Tomo 1: La voluntad del saber. $25^{\mathrm{a}}$ Ed. Siglo XXI Editores, S.A. de C.V., Madrid, 1998. Disponible en: http:/ / BIBLIOTECA.D2G.COM La microfísica del poder, Las ediciones de la Piqueta, Madrid, 1979.

Un diálogo sobre el poder y otras conversaciones. 1ª. Ed. Alianza Editorial. Madrid, 2001. Las palabras y las cosas. Siglo XXI Editores, S.A. de C.V., Madrid, 1968.

* GaRland, David: Castigo y Sociedad Moderna. Un estudio de teoría social, Siglo XXI Editores, México D.F., 1999. 2005. La cultura del control. Crimen y orden social en la sociedad contemporánea, Gedisa, México,

* V. GIES, Stephen; GAINEY, Randy; COHEN, Marcia; HEALY, Eoin; DUPLANTIER, Dan; YEIDE, Martha; BEKELMAN, Alan; BOBNIS, Amanda; HOPPS, Michael: Monitoring High-Risk Sex Offenders With GPS Technology: An Evaluation of the California 
REJ - Revista de Estudios de la Justicia - No 18 - Año 2013

Supervision Program, Final Report. Office of Research and Evaluation National Institute of Justice. Washington DC, 2012.

* GONZÁLEZ, Cristina: El control electrónico en el sistema penal, Tesis Doctoral, Universidad Autónoma de Barcelona, 2008.

* HeRnández Jiménez, Norberto: "Los sistemas de vigilancia electrónica como sustitutivos de la prisión bajo una perspectiva analítico-económica del derecho", CONTEXTO Revista de Derecho y Economía 36, 2012.

* IGLESIAS, Miguel Ángel y PÉREZ, Juan Antonio: "La pena de localización permanente y su seguimiento con medios de control electrónico", Anuario de Derecho Constitucional Latinoamericano, 2006.

* international association OF CHIEFs OF POLICE and AMERICAN PROBATION AND PAROLE ASSOCIATION: Tracking Sex Offenders with Electronic Monitoring Technology: Implications and Practical Uses for Law Enforcement, 2008.

* KILGORE, James: Progress or More of the Same? Electronic Monitoring and Parole in the Age of Mass Incarceration, Center for African Studies University of Illinois, 2012.

* KILLIAS, Martin; GILLIE’RON, Gwladys; KISSLING, Izumi, y VILLETAZ, Patrice: “Community Service Versus Electronic Monitoring-What Works Better?”, British Journal of Criminology Advance, 2010.

* Larraín, Jorge: El concepto de ideología. Vol. 4: Postestructuralismo, Postmodernismo y Postmarxismo, LOM Ediciones, Santiago, 2010.

* LARRAURí Pijoán, Elena: "Suspensión y sustitución de la pena en el nuevo Código Penal". Estudios penales y criminológicos, ISSN 1137-7550, № 19, 1996. Disponible en: bttp:/ / dialnet.unirioja.es/servlet/articulo? codigo $=2104185$

"La economía política del castigo". Revista Estudios de la Justicia 11, Facultad de Derecho Universidad de Chile, 2009.

* LIPSEY, Mark; HOWELL, James; KELLY, Marion; CHAPMAN, Gabrielle; CARVER, Darin: Improving the effectiveness of juvenile justice programs. A new perspective on evidence based practice. Center for juvenile justice reform, Georgetown University, Washington DC, 2010.

* MARTINOVIC, Marietta: The punitiveness of electronically monitores community based programs. Paper presented at the Probation and Community Corrections: Making the Community Safer Conference convened by the Australian Institute of Criminology and the Probation and Community Corrections Officers' Association Inc. Victoria, 2002.

* MAÑAlCH, Juan Pablo: "Pena y Ciudadanía", Revista de Estudios de la Justicia 6, Facultad de Derecho Universidad de Chile, 2006.

* MiNisteriO DE JUSTICIA. Nueva Ley $N^{\circ}$ 18.216. Análisis de las modificaciones introducidas por la ley 20.603. Material para capacitación. Santiago, 2012.

* NELLIS, Mike y VANHAELEMEESCH, Delphine: Conference Report. Towards a Gold Standard in The Practice of Electronic Monitorin, 2012. Disponible en: http:/ / www.cepprobation.org/uploaded_files/Final-report-EM2012.pdf

* office of pRogram pOLICy ANALisys AND gOVERMENT ACCOUNTABILITY AN OFFICE OF THE FLORIDA LEGISLATURE: Electronic monitoring should be better targeted to the most dangerous offenders, Florida, 2005.

* OREgON DEPARTMENT OF CORRECTION: The Effectiveness of Community-Based Sanctions in Reducing Recidivism, Oregon Department of Corrections, 2002.

* PADGETT, Kathy, BALES, William y BLOMBERG, Thomas: "Under Surveillance: an empirical test of the effectiveness and consequences of electronic monitoring", Florida State University 5, 2006. Disponible en: http:/ / ccoso.org/ undersurveillance.pdf

* PATCHIN, Justin; KEVELES, Gary: Alternatives to incarceration an evidence-based research review. Northwest Wisconsin Criminal Justice Management Conference, Wisconsin, 2004. 
Peña - Monitoreo telemático...

* PAYNE, Brian y DEMICHELE, Mathew: "Electronic supervision for sex offenders: Implications for workload, supervision goals, versatility, and policy making", Journal of Criminal Justice 38, 2010.

* PEÑA, Wilmar: "La violencia simbólica como reproducción biopolítica del poder". Revista Latinoamericana de Bioética 9, 2009.

* RENZEMA, Marc y MAYO-WILSON, Evan: Can electronic monitoring reduce crime for moderate to high-risk offenders? Journal of Experimental Criminology (2005) 1: 215-237.

* RePÚblica de PANAmÁ. ministerio PÚBlico. PROCURAduría GENERAL DE LA NACIÓN: Resolución N 46: "Que implementa de manera permanente el Programa de Sistema de Localización Telemática a través del uso del Brazalete Electrónico de Monitoreo para garantizar el cumplimiento de Medidas Cautelares”, 2009.

* RUSCHE, George y KIRCHHEIMER, Otto: Pena y estructura social, Temis, Bogotá, 1984.

* TORRES Rosell, Nuria: "Libertad vigilada y seguimiento continuado de penados: contenido e implicaciones político criminales". Revista Electrónica de Ciencia Penal y Criminología (en línea), 2012.

* UGARTE, Javier: Biopolítica. Un análisis de la cuestión. En: http:// www.biopolitica.cl/docs/Biopolitica_un_analisis.pdf

* U.S. Departament OF JUSTICE. OFFICE OF JUSTICE PROgRAMS. NATIONAL INSTITUTE OF JUSTICE: Electronic Monitoring Reduces Recidivism, Washington DC, 2011.

* WACQUANT, Loïc: Castigar a los pobres: El gobierno neoliberal de la inseguridad social, Gedisa, Barcelona, 2010.

* WEBER, Jonas y NETT, Jachen: COST Action IS 1106: Offender Supervision in Europe Country Report for Switzerland. 2011. Disponible en: www.offendersupervision.eu/wpcontent/ uploads/2013/04/OSE-progress-report-2013.pdf.

* ZAFFARONI, Eugenio Raúl: “¿Qué hacer con la pena? Las alternativas a la prisión”. En: Cuadernos para la Reforma de la Justicia. 2. Las penas sustitutivas de prisión. Disponible en: bttp:/ / criminet.ugr.es/recpc/ recpc_03-05.btml.

* ŽIŽEK, Slavoj: Sobre la violencia. Seis reflexiones marginales. Ed. Paidós, Buenos Aires, 2009. 